\title{
The significance of phytoplankton photo-adaptation and benthic-pelagic coupling to primary production in the South China Sea: Observations and numerical investigations
}

\author{
Kon-Kee Liu ${ }^{\mathrm{a}, *}$, Ying-Jie Chen ${ }^{\mathrm{b}}$, Chun-Mao Tseng ${ }^{\mathrm{b}}$, I.-I. Lin ${ }^{\mathrm{c}}$, \\ Hong-Bin Liu ${ }^{\mathrm{d}}$, Anond Snidvongs ${ }^{\mathrm{e}}$ \\ anstitute of Hydrological Sciences, National Central University, Jungli, Taoyuan 32001, Taiwan, ROC \\ ${ }^{\mathrm{b}}$ Institute of Oceanography, National Taiwan University, Taiwan, ROC \\ ${ }^{\mathrm{c}}$ Department of Atmospheric Sciences, National Taiwan University, Taiwan, ROC \\ ${ }^{\mathrm{d}}$ Atmosphere, Marine and Coastal Environment (AMCE) program, and Department of Biology, \\ Hong Kong University of Science and Technology, Clear Water Bay, Hong Kong \\ ${ }^{\mathrm{e}}$ Chulalongkorn University, Bangkok, Thailand
}

Accepted 13 May 2007

Available online 24 July 2007

\begin{abstract}
The primary production in the South China Sea (SCS) has been assessed by a coupled physical-biogeochemical model with a simple NPZD ecosystem [Liu et al., 2002. Monsoon-forced chlorophyll distribution and primary production in the SCS: observations and a numerical study. Deep-Sea Research I 49(8), 1387-1412]. In recent years there have been an increasing number of observations in the SCS that may be used to check the validity of the previous approach. The coupled model of the SCS mentioned above employs a photo-adaptation scheme for the phytoplankton growth and uses the simplest bottom boundary condition of an inert benthic layer. These adopted schemes are checked against observations at the South-East Asian Time-series Study (SEATS) Station in the northern SCS and in the Gulf of Thailand. Numerical experiments with or without photo-adaptation or active benthic processes are carried out in this study. Additional experiments are performed with different parameters used for these processes. The observations at the SEATS Station provide direct evidence for the variable chlorophyll-to-nitrogen ratio in phytoplankton as required by photo-adaptation. It is concluded that a photo-adaptation scheme is critical to the phytoplankton growth, especially for the development of the subsurface chlorophyll maximum (SCM). Without photo-adaptation, the average value of the vertically integrated primary production (IPP) over the whole SCS domain would be $35 \%$ lower. It is noted that, the modeled SCM occurs at depths shallower than observations due to physical as well as biological processes employed by the model. Increasing the upper limit of the chlorophyll-to-nitrogen ratio, as suggested by observations, enhances chlorophyll level in the lower part of the euphotic zone and raises primary productivity in areas with rich nutrient supply. The observed values of the IPP in the Gulf of Thailand clearly demonstrate the importance of the benthic-pelagic coupling to the nutrient cycle. Without benthic nutrient regeneration the model grossly underestimates primary production due to failure to build up the nutrient reserve in the Gulf. On the other hand, a fully regenerated flux of particulate organic nitrogen at the sea floor without denitrification produces too strong a primary production. The improved model uses a higher upper limit for the chlorophyll-to-phytoplankton ratio of $3.5 \mathrm{~g} \mathrm{Chl} / \mathrm{mol} \mathrm{N}$ and adopts benthic processes of a coupled
\end{abstract}

*Corresponding author. Tel.: + 88634223354 ; fax: + 88634222894 .

E-mail address: kkliu@ncu.edu.tw (K.K. Liu). 
nitrification-denitrification scheme with denitrification consuming $14 \%$ of the detritus flux at the bottom. The model predicts a mean annual IPP value of $406 \mathrm{mg} \mathrm{C} \mathrm{m}^{-2} \mathrm{~d}^{-1}$ for the SCS, which is $44 \%$ higher than that predicted by the original model. The increase can be broken down to $39 \%$ attributed to the benthic nutrient regeneration and $5 \%$ to the enhanced photo-adaptation. The average IPP is $390 \mathrm{mg} \mathrm{C} \mathrm{m}^{-2} \mathrm{~d}^{-1}$ for the basin region $(>200 \mathrm{~m})$ and $429 \mathrm{mg} \mathrm{C} \mathrm{m}^{-2} \mathrm{~d}^{-1}$ for the shelf region $(<200 \mathrm{~m})$, both of which compare favorably with observed mean values. The model also predicts a mean nitrogen removal flux of $0.16 \mathrm{mmol} \mathrm{N} \mathrm{m}^{-2} \mathrm{~d}^{-1}$ during denitrification for the shelf region.

(C) 2007 Elsevier Ltd. All rights reserved.

Keywords: Biogeochemical; Nutrient regeneration; Denitrification; Gulf of Thailand; SEATS; South China Sea

\section{Introduction}

Driven by the alternating monsoons, the biogeochemistry of the South China Sea (SCS) is very dynamic and potentially sensitive to climate change. Such a premise has inspired new biogeochemical observations (Wong et al., 2002; Tseng et al., 2005) and modeling work (e.g., Liu et al., 2002). A better understanding of the SCS biogeochemistry is essential for the interpretation of paleo records in the SCS obtained during paleoceanographic expeditions, which have flourished in the last decade (Chen et al., 1999; Wang et al., 2004). Despite the importance of its biogeochemical system, the SCS has received much less attention than the other prominent monsoon-driven system, namely, the Arabian Sea (e.g., Smith, 2001).

Liu et al. (2002) developed a coupled physicalbiogeochemical model for the SCS (Fig. 1) and estimated the annual mean value of the vertically integrated primary production (IPP) of the SCS model output domain to be $280 \mathrm{mg} \mathrm{C} \mathrm{m}^{-2} \mathrm{~d}^{-1}$, which is considerably lower than the estimate based on the SeaWiFS chlorophyll data and the algorithm of vertically generalized production model (VGPM) of Behrenfeld and Falkowski (1997). In recent years, the South-East Asian Time-series Study (SEATS) has accumulated a wealth of observations in the SCS (Tseng et al., 2005) that prove useful for better understanding of critical biogeochemical processes. In addition, there have been a few field studies of primary productivity in the SCS (Ning et al., 2004; Chen, 2005), which may serve as criterion for comparison of different assessment approaches. Moreover, some observations of primary production in the Gulf of Thailand have become available to us for the comparison.

The coupled model that Liu et al. (2002) developed adopts a photo-adaptation scheme for the phytoplankton growth. Photo-adaptation in the model is manifested as a variable chlorophyll-to- nitrogen ratio in phytoplankton, which is regulated by light intensity and availability of nutrients (Geider, 1987; Doney et al., 1996). On the other hand, the ecosystem model developed by Fasham et al. (1990) adopts a constant chlorophyll-tonitrogen ratio in phytoplankton of $1.59 \mathrm{~g} \mathrm{Chl} /$ molN, which is still widely used. We intend to check the validity of the photo-adaptation scheme by comparing model results against observations at the SEATS Station and to assess the importance of photo-adaptation to phytoplankton growth by numerical experiments.

There are five levels of benthic-pelagic coupling schemes with increasing complexity used in biogeochemical models (Soetaert et al., 2000). The model of Liu et al. (2002) employs the simplest bottom boundary condition of an inert benthic layer, which is designated as Level 0 by these authors. For practical reasons, they recommend schemes of intermediate complexity, namely, Level 2 scheme, in which all particulate organic nitrogen that hits the bottom gets regenerated, or Level 3 scheme, which is a vertically integrated dynamic benthic layer. Recently, a biogeochemical model developed for the Mid Atlantic Bight adopts a benthic-pelagic coupling scheme, which is between Levels 2 and 3 and takes denitrification into consideration (Fennel et al., 2006). Because benthic-pelagic coupling is most critical to the shelf ecosystem, we intend to use observations of primary productivity in the Gulf of Thailand to evaluate the performance of models with different benthic processes.

The purpose of this study is to understand the significance of phytoplankton photo-adaptation and benthic-pelagic coupling to primary productivity in the SCS and to improve the coupled physical-biogeochemical model. Using the improved model, we attempt to re-assess the mean annual primary production in the SCS, which is to be compared with recently observed IPP values as well as those derived from SeaWiFS chlorophyll 


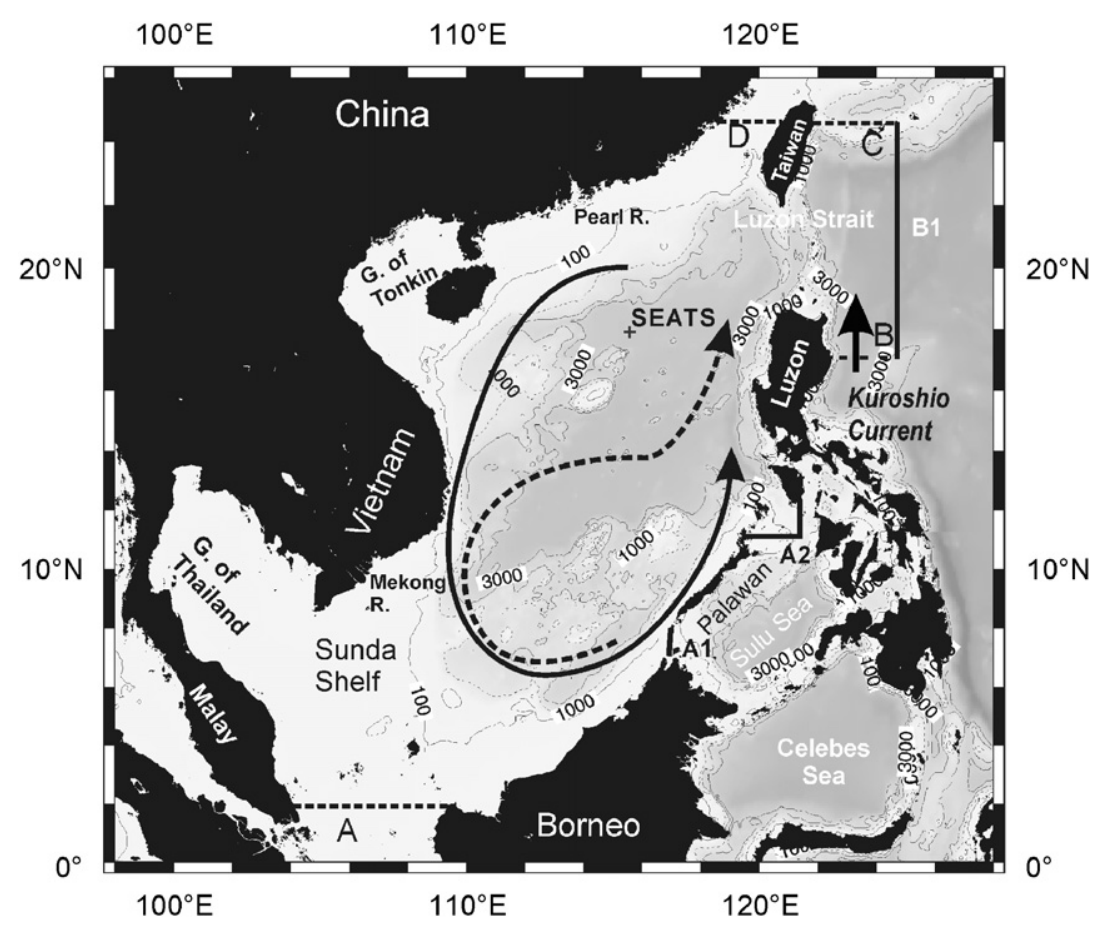

Fig. 1. Map, with isobaths (in meters), of the South China Sea. The solid and the dashed curves with arrows indicate the winter and summer jets, respectively. The heavy solid and dashed lines represent closed and open ocean boundaries of the model domain, respectively. The SEATS Station $\left(18^{\circ} \mathrm{N}, 116^{\circ} \mathrm{E}\right)$ is indicated by the cross $(+)$ in the northern SCS (see text).

data. We also attempt to estimate denitrification rates in the SCS.

\section{Study area}

The SCS (Fig. 1), which spans from $1.5^{\circ} \mathrm{N}$ to $24^{\circ} \mathrm{N}$, covers a total area of 3.35 million $\mathrm{km}^{2}$ (Liu et al., 2006). It has extensive continental shelves to the northwest and south and a deep basin in the central region attaining a depth of $5000 \mathrm{~m}$ (NGDC, 2001). The shelf region with bottom depth less than $200 \mathrm{~m}$ comprises about $40 \%$ of the area.

The currents within the SCS proper are rather weak, whereas the relatively strong Kuroshio flows by the Luzon Strait (Fig. 1) with partial intrusion into the SCS. In winter the intrusion is most evident (Shaw, 1991; Xue et al., 2004) with the intruding water following the cyclonic circulation driven by the persistent northeast monsoon (Shaw and Chao, 1994). The southward jet off Vietnam turns cyclonically near the Sunda Shelf due to the topographic blockage, but some of the surface waters continue to flow southward entering the Java Sea. In summer the southwest monsoon reverses the coastal jet off Vietnam with the northward flow veering off the coast at about $12^{\circ} \mathrm{N}$ (Fig. 1). The seaward current crosses the SCS interior and turns cyclonically in the northern basin (Shaw and Chao, 1994). The exchange of water between the SCS and its surroundings seas has been studied since the 1960s. Previously estimated bimonthly transports (Wyrtki, 1961) through the major exchange channels, namely Luzon, Taiwan Straits and Sunda Shelf-Java Sea are used to constrain regional circulation models (Shaw and Chao, 1994; Wu et al., 1999), including the models used in this study.

The monsoons drive upwelling in three major regions in the SCS (Chao et al., 1996; Shaw et al., 1996; Udarbe-Walker and Villanoy, 2001): off northwestern Luzon and around the shelf break in northern Sunda Shelf in winter and off the central Vietnamese coast in summer (Fig. 1). The chlorophyll distribution is closely related to monsoonal forcing (Liu et al., 2002). Elevated chlorophyll concentrations occur in the afore-mentioned upwelling areas during monsoon seasons (Liu et al., 2002; Chen et al., 2006), while the lowest values occur during the inter-monsoon periods. The winter maxima are stronger and more extensive than the 
summer maxima under the southwest monsoon, which is weaker than the northeast monsoon.

The Gulf of Thailand (Fig. 2) is a semi-enclosed tropical sea with an area of $263,000 \mathrm{~km}^{2}$ and a mean depth of $44 \mathrm{~m}$ (Liu et al., 2006). The Gulf is separated from the SCS by a sill at about $60 \mathrm{~m}$ below surface (Fig. 2). The Gulf is well stratified throughout the year. The circulation in the Gulf is controlled mainly by local wind forcing in summer and the general circulation in the SCS in winter (Liu et al., 2006). In winter, there is a strong surface inflow along the western coast of the Gulf, while there may be some weak surface outflow along the eastern coast. Most of the water inflow returns to the SCS via the bottom layer. Under the northeast monsoon in winter, low-salinity water from the Mekong outflow region also enters the Gulf

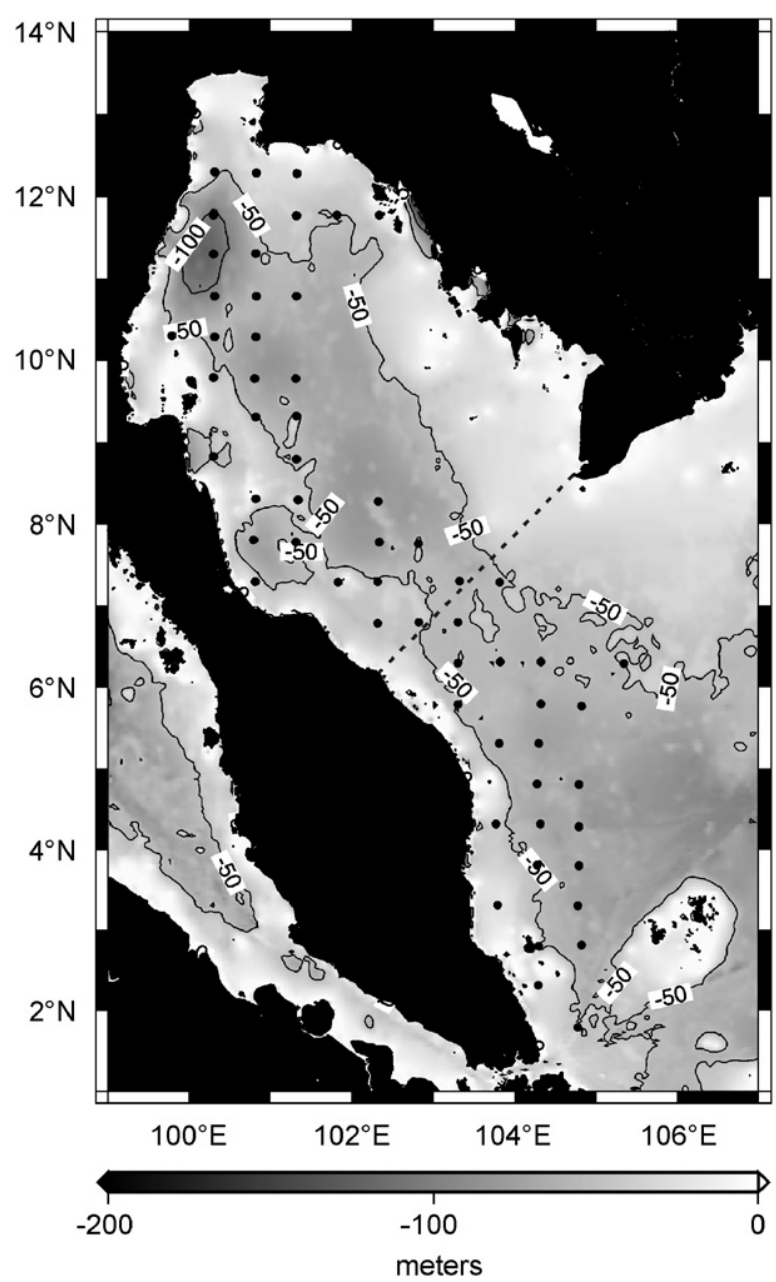

Fig. 2. Map of the Gulf of Thailand and vicinities. The dashed line indicates the outer boundary of the Gulf. The dots represent localities of the stations of the surveys (see text).
(Wattayakorn et al., 1998). In summer, relatively high-salinity surface water from the SCS may intrude along the western side for a few $100 \mathrm{~km}$ into the Gulf, but surface water of the remaining part flows outward (Wattayakorn et al., 1998). This outward flow is compensated by the net inflow of bottom water.

\section{Materials and methods}

\subsection{Sampling and measurements at SEATS site}

Measurements of chlorophyll $a(\mathrm{Chl}-a)$, particulate organic carbon (POC) and particulate nitrogen (PN) were carried out on seawater samples collected on 10 cruises for hydrographic survey at the SEATS Station between November 1999 and May 2004 (Table 1). The CTD-Rosette sampler fitted with 20-L Go-Flo bottles (General Oceanic) were used for the sampling on cruises on board $\mathrm{R} / \mathrm{V}$ Ocean Researcher I (OR1) and R/V Ocean Researcher III (OR3). All the samples for this study were collected from the top $200 \mathrm{~m}$ of the water column at 10-18 depths.

Seawater samples of $2 \mathrm{~L}$ in volume for Chl- $a$ analysis were immediately filtered through $\mathrm{GF} / \mathrm{F}$ filters (Whatman, $47 \mathrm{~mm}$ ), which were stored at $-20{ }^{\circ} \mathrm{C}$. The phytoplankton pigments retained on $\mathrm{GF} / \mathrm{F}$ filters was extracted in $90 \%$ acetone (Strickland and Parsons, 1972). The Chl- $a$ concentration in the extract was measured with a fluorometer (Turner 10-AU-005).

Samples of suspended particulate matter (SPM) for POC and PN analyses were collected by filtering $2-5 \mathrm{~L}$ of water samples through $\mathrm{GF} / \mathrm{F}$ filters (Whatman, $25 \mathrm{~mm}$ ) under pressure of less than $200 \mathrm{~mm}$ $\mathrm{Hg}$. Filtered samples were wrapped in preheated

Table 1

Sampling cruises

\begin{tabular}{llllll}
\hline R/V & Cruise & Date & Sta & $\begin{array}{l}\text { Longitude } \\
\left({ }^{\circ} \mathrm{E}\right)\end{array}$ & $\begin{array}{l}\text { Latitude } \\
\left({ }^{\circ} \mathrm{N}\right)\end{array}$ \\
\hline OR3 & 585 & 23November 1999 & $\mathrm{S} 1$ & 116.004 & 17.999 \\
OR3 & 600 & 17 January 2000 & $\mathrm{S} 1$ & 115.998 & 18.001 \\
OR3 & 607 & 13 March 2000 & $\mathrm{S} 1$ & 116.001 & 18.002 \\
OR3 & 629 & 23 May 2000 & $\mathrm{S} 1$ & 116.001 & 18.001 \\
OR3 & 644 & 25 July 2000 & $\mathrm{S} 1$ & 116.006 & 17.999 \\
OR3 & 657 & 18 October 2000 & KK1 & 115.576 & 18.251 \\
OR1 & 673 & 20 January 2003 & KK1 & 115.708 & 18.365 \\
OR1 & 705 & 17 December 2003 & KK1 & 115.626 & 18.228 \\
OR1 & 711 & 15 March 2004 & KK1 & 115.669 & 18.383 \\
OR1 & 717 & 5 May 2004 & KK1 & 115.671 & 18.385 \\
\hline
\end{tabular}


$\left(450{ }^{\circ} \mathrm{C}\right)$ aluminum foil and preserved in a freezer at $-20^{\circ} \mathrm{C}$. After returned to the laboratory, filters were acidified with $1 \mathrm{~N} \mathrm{HCl}$ and dried in an oven $\left(50{ }^{\circ} \mathrm{C}\right)$ for $24 \mathrm{~h}$ for decarbonation prior to analysis. The dried filters were wrapped in tin capsules for determination of carbon and nitrogen contents in a Fison $1500 \mathrm{CHN}$ Analyzer. Blank filters wrapped in tin capsules in five replicas were analyzed for the determination of the blank value. Reagent grade acetanilide was used for calibration purposes. The precision of the elemental analysis is better than $\pm 0.06 \mu \mathrm{M}$ for POC and $\pm 0.025 \mu \mathrm{M}$ for $\mathrm{PN}$.

\subsection{Surveys in the Gulf of Thailand}

Two hydrographic surveys on board of $\mathrm{M} / \mathrm{V}$ Seadec and $\mathrm{M} / \mathrm{V}$ Platoo, respectively, were carried out at 60 stations in the Gulf of Thailand and vicinity (Fig. 2) in September and October, 1995 (Musikasung et al., 1997). Underwater light intensity was measured with a Lux-meter (Alec Electronics Model SPI-9W). In situ fluorescence was measured with a Sea Tech submersible fluorometer. Conversion of the fluorometer data to Chl- $a$ concentration was done by calibrating the fluorescence against measured Chl- $a$ concentrations (Strickland and Parsons, 1972).

Primary production (PP) was measured at five stations by the ${ }^{14} \mathrm{C}$ assimilation method (Parsons et al., 1984). Each water sample was transferred to a suite of $500-\mathrm{mL}$ glass bottles. Four of them were clear glass bottles and one was a dark glass bottle. One of the samples in clear glass bottle was used as the control. All bottles except the controls were inoculated with $2.52 \mu \mathrm{Ci} \mathrm{NaH}^{14} \mathrm{CO}_{3}$. All bottles were incubated in situ for $3 \mathrm{~h}$. Following incubation, the samples were filtered through $\mathrm{GF} / \mathrm{F}$ filters (Whatman, $25 \mathrm{~mm})$. The filters then were placed in scintillation vials and stored frozen in darkness. After returned to the laboratory, the total activity on filters was counted in a liquid scintillation counter (Shimatzu GC-9A 2700TR). The $P^{\mathrm{B}}-E$ curve was constructed from the incubation results. Primary production at each depth was calculated from the measured underwater light intensity at sea surface, in situ Chl- $a$ concentration, and the photosynthetic parameters from incubation (Jassby and Platt, 1976).

\subsection{Satellite data}

Chlorophyll data derived from ocean-color images were used to calculate the monthly primary production in the SCS with the VGPM algorithm (Behrenfeld and Falkowski, 1997). The ocean color data are the SeaWiFS Level 3 Monthly Standard Mapped Image of Chlorophyll $a$ concentration data from 1998 to 2002 (http://daac.gsfc.nasa.gov/data/ dataset/SEAWIFS/01_Data_Products/index.html).

The VGPM algorithm for estimation of the IPP is expressed below:

$$
\mathrm{IPP}_{\mathrm{eu}}=0.66125 P_{\mathrm{opt}}^{\mathrm{B}}\left[E_{0} /\left(E_{0}+4.1\right)\right] C_{\mathrm{sat}} Z_{\mathrm{eu}} D_{\mathrm{IRR}},
$$

where $\mathrm{IPP}_{\mathrm{eu}}$ is the daily euphotic zone-IPP $\left(\mathrm{mg} \mathrm{C} \mathrm{m}{ }^{-2} \mathrm{~d}^{-1}\right), C_{\text {sat }}$ the surface chlorophyll concentration $\left(\mathrm{mg} \mathrm{Chl} \mathrm{m}^{-3}\right), D_{\text {IRR }}$ the daily photoperiod (h), $E_{0}$ the sea surface daily photosynthetically active radiation (PAR) (Einstein $\left.\mathrm{m}^{-2} \mathrm{~d}^{-1}\right), Z_{\text {eu }}$ the depth of the euphotic zone $(\mathrm{m}), C_{\text {TOT }}$ the vertically integrated Chl- $a$ stock in the euphotic zone, and $P_{\mathrm{opt}}^{\mathrm{B}}$ is the optimal specific primary productivity.

The vertically integrated Chl- $a$ stock in the euphotic zone was derived from the SeaWiFS surface Chl- $a$ concentration following the algorithm of Behrenfeld and Falkowski (1997). The depth of the euphotic zone was in turn calculated from the vertically integrated Chl- $a$ stock (Morel and Berthon, 1989). The optimal specific primary productivity $\left(\mathrm{mgCmg} \mathrm{Chl}^{-1} \mathrm{~h}^{-1}\right)$ was calculated from the empirical equation provided by Behrenfeld and Falkowski (1997).

Aside from surface Chl- $a$ concentration, the major input data for the VGPM include sea surface daily PAR, sea-surface temperature (SST), and length of solar radiation. The PAR data are the SeaWiFS Level 3 monthly standard mapped image of PAR, taken from the GES distributed active archive center of the SeaWiFS Project of NASA (http://daac.gsfc.nasa.gov/data/dataset/SEAWIFS/ 01_Data_Products/index.html).

SST data are AVHRR Oceans Pathfinder global equal-angle best SST with $9 \times 9 \mathrm{~km}^{2}$ resolution taken from the Physical Oceanography Distributed Active Archive Center (http://podaac.jpl.nasa.gov/products/ product102.html). The lengths of solar radiation are taken from the data bank of IMCS Ocean Primary Productivity Team (http://marine.rutgers.edu/opp/).

\section{Model descriptions}

\subsection{The original model}

The three-dimensional numerical model of the SCS with coupled physics and biogeochemistry 
(Liu et al., 2002) was based on a previously established hydrodynamic model (Shaw and Chao, 1994; Chao et al., 1996). The model has a horizontal resolution of $0.4^{\circ}$ in the domain $2-24.8^{\circ} \mathrm{N}$ and 99- $124.6^{\circ} \mathrm{E}$ and 21 layers in the vertical. The output domain, which is stripped of the zone next to model boundaries, ranges from 4 to $23.6^{\circ} \mathrm{N}$ and from 99 to $121.4^{\circ} \mathrm{E}$ with an area of 3.12 million $\mathrm{km}^{2}$.

The biogeochemical model has four compartments, dissolved inorganic nitrogen (DIN), phytoplankton (Phy), zooplankton (Zop) and detritus (Det) with a variable chlorophyll-to-nitrogen or $\mathrm{Chl} /$ Phy ratio $(R)$ in phytoplankton. Consequently, chlorophyll (Chl) is also set as a state variable, which is expressed in units of $\mathrm{mg} \mathrm{m}^{-3}$. All state variables except $\mathrm{Chl}$ are expressed in terms of nitrogen concentration $\left(\mathrm{mmol} \mathrm{N} \mathrm{m}^{-3}\right)$. The $\mathrm{Chl} / \mathrm{Phy}$ ratio depends on light and DIN availability. The time-dependent change of a biogeochemical tracer is determined by physical (advection and diffusion) and biogeochemical (production and consumption) processes. Major biogeochemical processes include phytoplankton growth, mortality, aggregation and zooplankton grazing, mortality, and detritus remineralization. Detritus is assumed to sink at the velocity of $10 \mathrm{~m} \mathrm{~d}^{-1}$, which is relative to water. The transformations between different biogeochemical tracers are regulated by several biogeochemical parameters. All mathematic expressions, initial and boundary conditions and forcing can be referred to the paper by Liu et al. (2002). The values of biogeochemical parameters (Fasham et al., 1990; McGillicuddy et al., 1995; Doney et al., 1996) are listed in Table 2.

After being initialized by the January temperature and salinity fields of climatological hydrography (Levitus, 1982) and the mean DIN field (Conkright et al., 1994), the model is driven by climatological

Table 2

Biogeochemical parameter values used by Liu et al. (2002)

\begin{tabular}{|c|c|c|c|c|}
\hline Parameters & Description & Units & Value & References \\
\hline$\kappa_{\mathrm{c}}$ & Light attenuation due to chlorophyll & $(\mathrm{mgChl} \mathrm{m})^{-1}$ & 0.048 & Fasham et al. (1990) \\
\hline$\kappa_{\mathrm{w}}$ & Light attenuation due to water & $\mathrm{m}^{-1}$ & 0.040 & Fasham et al. (1990) \\
\hline$Q_{10}$ & Temperature dependence of growth rate & & 1.884 & Doney et al. (1996) \\
\hline$\mu_{\mathrm{P} 20}$ & Maximum specific growth rate of phytoplankton at $20^{\circ} \mathrm{C}$ & $\mathrm{d}^{-1}$ & 2.10 & Doney et al. (1996) \\
\hline$\alpha$ & 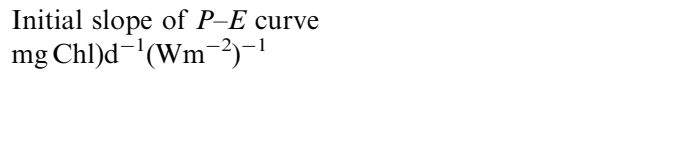 & $\begin{array}{l}(\mathrm{mmol} \mathrm{N} / \\
0.050\end{array}$ & $\begin{array}{l}\text { Doney } \\
\text { et al. } \\
\text { (1996) }\end{array}$ & \\
\hline$\kappa_{\mathrm{N}}$ & DIN half saturation concentration & $\operatorname{mmol~N~m}{ }^{-3}$ & 0.20 & Doney et al. (1996) \\
\hline$R_{\mathrm{H}}$ & $\begin{array}{l}\text { Minimum chlorophyll/phytoplankton ratio (for high } \\
\text { light condition) }\end{array}$ & $\mathrm{mgChl}(\mathrm{mmolN})^{-1}$ & 1.0 & Doney et al. (1996) \\
\hline$R_{\mathrm{L}}$ & $\begin{array}{l}\text { Maximum chlorophyll/phytoplankton ratio (for low } \\
\text { light condition) }\end{array}$ & $\operatorname{mg~Chl~}(\mathrm{mmolN})^{-1}$ & 2.5 & Doney et al. (1996) \\
\hline$E_{\mathrm{PA}}$ & Light level where photo-adaptation starts & $\mathrm{Wm}^{-2}$ & 90 & Doney et al. (1996) \\
\hline$\eta$ & Phytoplankton mortality rate constant & $\mathrm{d}^{-1}$ & 0.075 & Doney et al. (1996) \\
\hline$\omega$ & Phytoplankton aggregation rate constant & $\left(\mathrm{mmol} \mathrm{N} \mathrm{m}^{-3}\right)^{-1} \mathrm{~d}^{-1}$ & 0.10 & Doney et al. (1996) \\
\hline$\mu_{\mathrm{Z} 20}$ & Maximum specific growth rate of zooplankton at $20^{\circ} \mathrm{C}$ & $\mathrm{d}^{-1}$ & 1.0 & Fasham et al. (1990) \\
\hline$\lambda$ & Ivlev grazing constant & $\left(\mathrm{mmol} \mathrm{N} \mathrm{m}^{-3}\right)^{-1}$ & 1.0 & $\begin{array}{l}\text { McGillicuddy et al. } \\
\text { (1995) }\end{array}$ \\
\hline$\gamma$ & Fraction of grazing loss & & 0.25 & $\begin{array}{l}\text { McGillicuddy et al. } \\
\text { (1995) }\end{array}$ \\
\hline$N_{1}$ & Linear zooplankton mortality rate constant & $d^{-1}$ & 0.11 & $\begin{array}{l}\text { McGillicuddy et al. } \\
\text { (1995) }\end{array}$ \\
\hline $\mathrm{N}_{2}$ & Quadratic zooplankton mortality rate constant & $\left(\mathrm{mmol} \mathrm{N} \mathrm{m}{ }^{-3}\right)^{-1} \mathrm{~d}^{-1}$ & 0.52 & $\begin{array}{l}\text { McGillicuddy et al. } \\
\text { (1995) }\end{array}$ \\
\hline$\varepsilon_{1}$ & $\begin{array}{l}\text { Fraction of linear rate of zooplankton loss, that turns } \\
\text { into detritus }\end{array}$ & & 0.75 & $\begin{array}{l}\text { McGillicuddy et al. } \\
\text { (1995) }\end{array}$ \\
\hline$\varepsilon_{2}$ & $\begin{array}{l}\text { Fraction of quadratic rate of zooplankton loss, that turns } \\
\text { into detritus }\end{array}$ & & 0.50 & $\begin{array}{l}\text { McGillicuddy et al. } \\
\text { (1995) }\end{array}$ \\
\hline$\delta$ & Remineralisation rate constant of detritus & $\mathrm{d}^{-1}$ & 0.10 & Doney et al. (1996) \\
\hline$w_{\sin k}$ & Vertical velocity of detritus relative to water & $\mathrm{md}^{-1}$ & -10 & Doney et al. (1996) \\
\hline$f_{\mathrm{B}}$ & Fraction of benthic regeneration & & 0 & \\
\hline
\end{tabular}


monthly mean winds (Hellerman and Rosenstein, 1983), monthly sea-surface temperature, and seasonal surface salinity. The flow field in the third year of the model run shows little changes from those in the previous years and the biogeochemical tracers also reach quasi-steady state (Shaw and Chao, 1994; Liu et al., 2002). Therefore, the output from the third year of the model runs is presented in all cases.

\subsection{Biogeochemical processes modified for numerical experiments}

In the numerical experiments carried out in this study, several processes are modified for the investigation of their impacts on the ecosystem behavior. The first one is the phytoplankton growth, which has the following form in the original model:

$$
\begin{aligned}
\text { Phytoplankton growth }= & \mu_{\mathrm{P}} \mathrm{Phy}[1-\exp \\
& \left.\times\left(-\alpha R_{\mathrm{H}} E / \mu_{\mathrm{P}}\right)\right] \\
& \times\left(R / R_{\mathrm{H}}\right)\left[\mathrm{DIN} /\left(\mathrm{DIN}+k_{\mathrm{N}}\right)\right],
\end{aligned}
$$

where $R=\mathrm{Chl} / \mathrm{Phy}, \mu_{\mathrm{P}}$ is the specific growth rate of phytoplankton, $\alpha$ is the initial slope of $P-E$ curve, $R_{\mathrm{H}}$ is the lower limit of $\mathrm{Chl} / \mathrm{Phy}$ ratio (for high light condition), $E$ is PAR, $k_{\mathrm{N}}$ is the half saturation concentration of DIN.

In the growth term, the time-rate of change of $R$ is dependent on light and DIN availability (Doney et al., 1996):

$$
\begin{aligned}
\mathrm{d} R / \mathrm{d} t= & \mu_{\mathrm{P}}\left[1-\exp \left(-\alpha R_{\mathrm{H}} E / \mu_{\mathrm{P}}\right)\right]\left(R / R_{\mathrm{H}}\right) \\
& \times\left\{\left[R_{\mathrm{L}}-\Delta R \min \left(E / E_{\mathrm{PA}}, 1\right)\right]\right. \\
& \left.\times\left[\mathrm{DIN} /\left(\mathrm{DIN}+k_{\mathrm{N}}\right)\right]-R\right\},
\end{aligned}
$$

where $\Delta R=R_{\mathrm{L}}-R_{\mathrm{H}}, R_{\mathrm{L}}$ is the upper limit of Chl/ Phy ratio (for low light condition), $E_{\mathrm{PA}}$ is the light level where photo-adaptation starts. For models without photo-adaptation, the phytoplankton growth term becomes:

Phytoplankton growth $=\mu_{\mathrm{P}} \mathrm{Phy}\left(1-\exp \left(-\alpha R_{\mathrm{H}} E / \mu_{\mathrm{P}}\right)\right)$

$$
\times\left(R_{0} / R_{\mathrm{H}}\right)\left[\mathrm{DIN} /\left(\mathrm{DIN}+k_{\mathrm{N}}\right)\right] \text {, }
$$

where $R_{0}$ is the fixed $\mathrm{Chl} / \mathrm{Phy}$ ratio of $1.59(\mathrm{~g} \mathrm{Chl} /$ mol N) as suggested by Fasham et al. (1990) and $R_{\mathrm{H}}$ serves as a unit conversion factor of 1 .

In the original model the detritus is assumed to be stored permanently in the sediments as it reaches the sea floor. Consequently, the boundary condition for detritus at the bottom is simply Det $=0$. For other biogeochemical tracers the bottom boundary condition is as follows:

$w C-k_{z}(\partial C / \partial z)=0$,

where $C$ is the concentration of the tracer, $w$ is the vertical velocity and $k_{z}$ is the vertical diffusivity. For a benthic layer, where detritus that hits the bottom is regenerated as DIN, then the bottom boundary condition for DIN becomes

$$
\begin{aligned}
& w \mathrm{DIN}-k_{z}(\partial \mathrm{DIN} / \partial z) \\
& =\max \left\{-f_{\mathrm{B}}\left[\left(w+w_{\sin k}\right) \operatorname{Det}-k_{z}(\partial \operatorname{Det} / \partial z)\right], 0\right\},
\end{aligned}
$$

where $w_{\sin k}$ is the vertical velocity of detritus relative to water and $f_{\mathrm{B}}$ is the fraction of nitrogen regeneration. For total regeneration, $f_{\mathrm{B}}$ is set to 1 ; for the inert benthic layer, it is set to 0 ; for a benthic layer with coupled nitrification and denitrification (Fennel et al., 2006), then $0<f_{\mathrm{B}}<1$.

For a bottom boundary with denitrification, the flux of DIN removed during denitrification is calculated as follows:

$$
\begin{aligned}
\text { Denitrification flux }= & \max \left\{-\left(1-f_{\mathrm{B}}\right)\left[\left(w+w_{\sin k}\right)\right.\right. \\
& \left.\left.\times \operatorname{Det}-k_{z}(\mathrm{\partial Det} / \partial z)\right], 0\right\} .
\end{aligned}
$$

In the original model, the biogeochemical processes are included only in the top $500 \mathrm{~m}$. In order to properly evaluate the denitrification flux, which is related to the flux of detritus reaching the sea floor, we carry out calculation of the detritus concentration throughout the water column.

\section{Observations and numerical experiments}

For observational results, we first report hydrographic measurements, including Chl- $a$ and particulate organic matter, at the SEATS Station. The emphasis is on the variability of the POC-tochlorophyll ratio in the top $100 \mathrm{~m}$, which is the manifestation of photo-adaptation. We then report results of measured primary productivity in the Gulf of Thailand. In each part we compare model output with observations. The main purpose is to explore how photo-adaptation and benthic-pelagic coupling influences primary productivity in the SCS. The selected numerical experiments to be discussed are listed in Table 3. 
Table 3

List of selected numerical experiments and parameters use

\begin{tabular}{llllll}
\hline Experiment & \multicolumn{2}{l}{ Photo-adaptation parameters } & \multicolumn{2}{c}{ Benthic parameter } \\
\cline { 2 - 5 } & $R_{\mathrm{H}}(\mathrm{g} / \mathrm{mol} \mathrm{N})$ & $\mathrm{OC}_{\text {Phy }} / \mathrm{Chl}(\mathrm{g} / \mathrm{g})$ & $R_{\mathrm{L}}(\mathrm{g} / \mathrm{mol} \mathrm{N})$ & $\mathrm{OCC}_{\text {Phy }} / \mathrm{Chl}(\mathrm{g} / \mathrm{g})$ & $f_{\mathrm{B}}$ \\
\hline P1B0 & 1.0 & 79.5 & 2.5 & 31.8 & 0 \\
P0B0 & $1.59^{*}$ & 50 & 3.5 & 22.7 & 0 \\
P2B0 & 1.0 & 79.5 & 2.5 & 31.8 & 0 \\
P1B1 & 1.0 & 79.5 & 2.5 & 31.8 & 0.86 \\
P1B2 & 1.0 & 79.5 & 3.5 & 22.7 & 0.86 \\
P2B2 & 1.0 & 79.5 & & \\
\hline
\end{tabular}

*The value represents $R_{0}$ of Eq. (4). Photo-adaptation parameters include the Chl/Phy ratio for high light $\left(R_{\mathrm{H}}\right)$ and low light $\left(R_{\mathrm{L}}\right)$. Their corresponding values for the $\mathrm{OC}_{\mathrm{phy}} / \mathrm{Chl}$ ratio are also listed. The benthic parameter is the degree of benthic nutrient regeneration $\left(f_{\mathrm{B}}\right)$. Experiment P1B0 is identical to the original model of Liu et al. (2002).

(A)

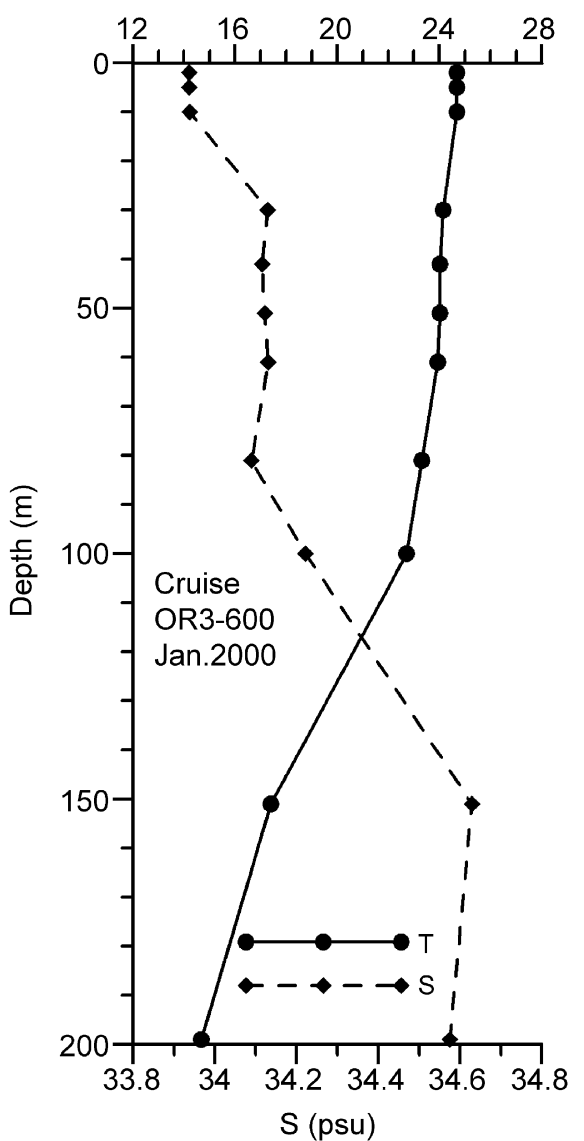

(B)

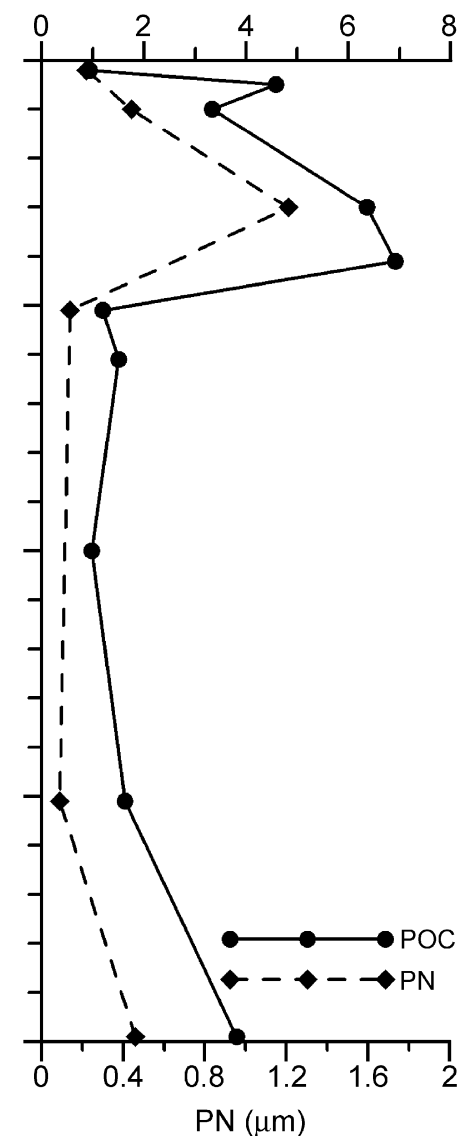

(C)

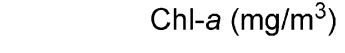

Fig. 3. Hydrography and selected biogeochemical profiles observed at the SEATS station on Cruise OR3-600 in January 2000. (A) Temperature and salinity profiles. (B) Profiles of POC and PN concentrations. (C) Profiles of Chl- $a$ and the POC/Chl- $a$ ratio.

\subsection{POC/chlorophyll ratio and photo-adaptation}

\subsubsection{Variability at SEATS Station}

The 10 cruises between November 1999 and May 2004 that provided samples for this study covered every season of the year. Two cruises are highlighted here to demonstrate the contrast between winter and summer. In January 2000, the temperature of seawater in the top $100 \mathrm{~m}$ (Fig. 3A) showed little variation consistent with the previously reported 
relatively thick mixed layer in late autumn and early winter (Tseng et al., 2005). The seasonal thermocline was deeper than $100 \mathrm{~m}$. The concentrations of POC (Fig. 3B) were high in the top $40 \mathrm{~m}$, reaching a maximum of $7 \mu \mathrm{M}$ and decreased abruptly to $2 \mu \mathrm{M}$ at $50 \mathrm{~m}$ depth. The concentrations of PN displayed similar trend. The Chl- $a$ profile (Fig. 3C) displayed a prominent subsurface maximum between depths of 30 and $70 \mathrm{~m}$ with a peak value of $0.7 \mathrm{mg} \mathrm{m}^{-3}$. The POC to Chl- $a$ ratio varied in a rather large range, from 24 to 11,430 ; the minimum corresponded to the subsurface Chl- $a$ maximum; the maximum occurred below the euphotic zone where phytoplankton diminishes and almost all the POC belongs to detritus.

The summer condition showed a much thinner mixed layer with the seasonal thermocline at about $35 \mathrm{~m}$ (Fig. 4A). The concentration of POC in the mixed layer fluctuated between 1 and $5 \mu \mathrm{M}$, apart from the rather large surface maximum at $9 \mu \mathrm{M}$
(Fig. 4B). Below the thermocline, the concentration of POC decreased to $2 \mu \mathrm{M}$ or lower. The Chl- $a$ profile again displayed a subsurface maximum, which was deeper, between depths of 50 and $80 \mathrm{~m}$, and weaker, at $0.4 \mathrm{mg} \mathrm{m}^{-3}$ (Fig. 4C). The POC to Chl- $a$ ratio varied in a narrower range, from 42 to 1540. It is noted that the minimum ratio is higher than the minimum observed on the winter cruise and rather close to the mean organic carbon (OC) to Chl- $a\left(\mathrm{OC}_{\mathrm{Phy}} / \mathrm{Chl}\right)$ ratio of 50 for phytoplankton.

The POC to PN relationship (Fig. 5) indicates the $\mathrm{C}-\mathrm{N}$ composition of particulate organic matter changes follows closely the Redfield ratio in the water column at SEATS. This confirms the adequacy of using Redfield ratio in the conversion from nitrogenbased quantities to carbon units in the model.

\subsubsection{Observed vs. modeled POC/chlorophyll ratio}

To account for photo-adaptation, the model employs a variable $\mathrm{Chl} / \mathrm{Phy}(R)$ ratio, which is
(A)

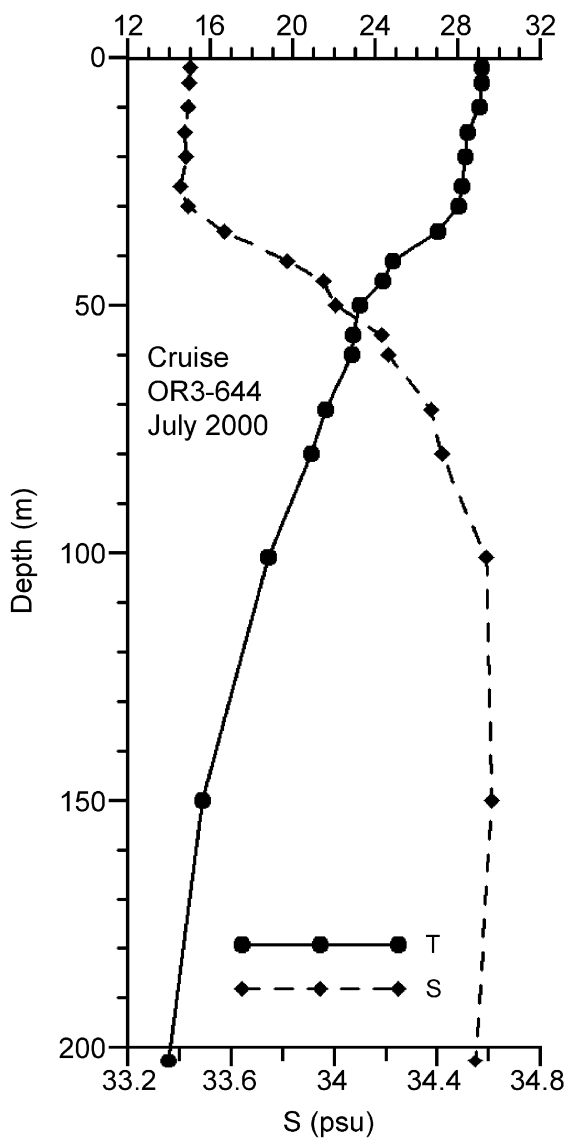

(B)

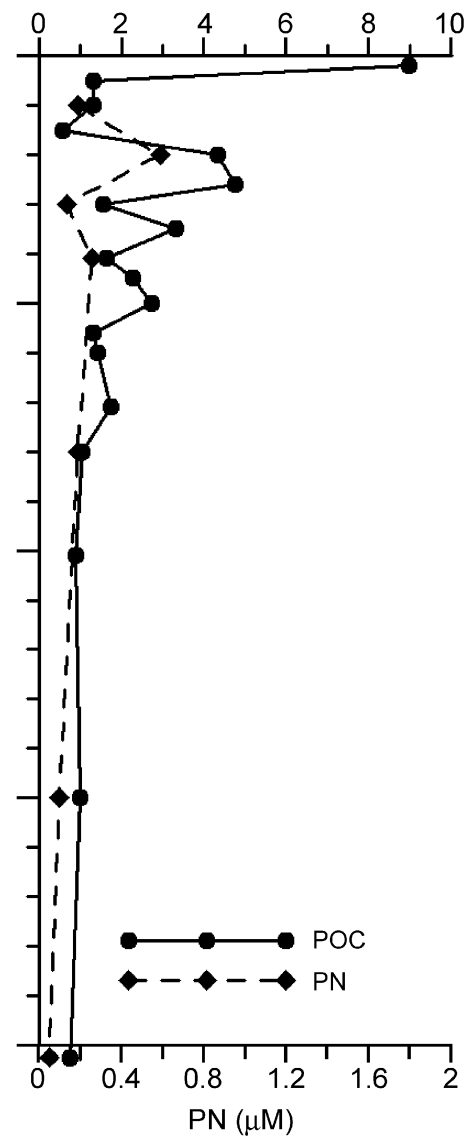

(C)

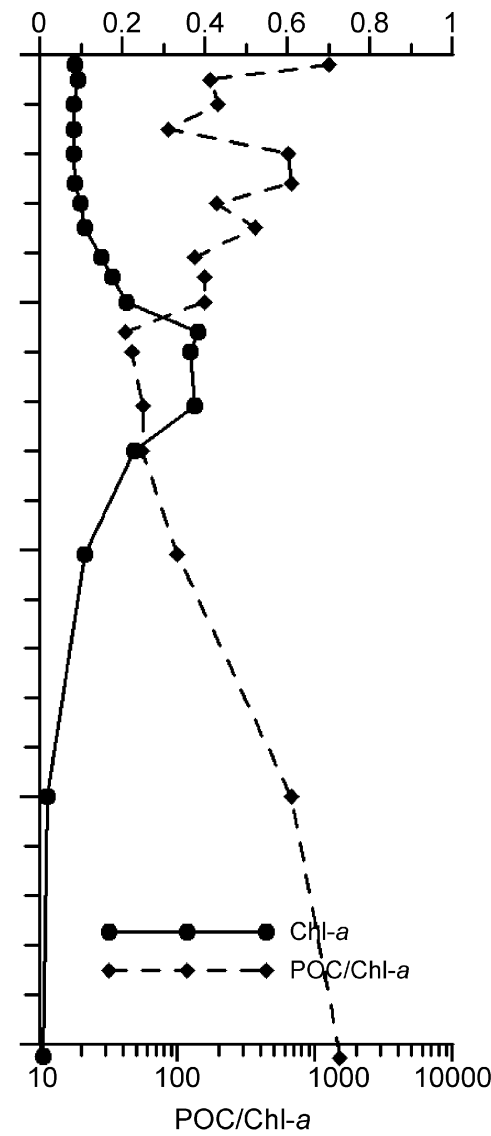

Fig. 4. The same as Fig. 3 except for Cruise OR3-644 in July 2000. 


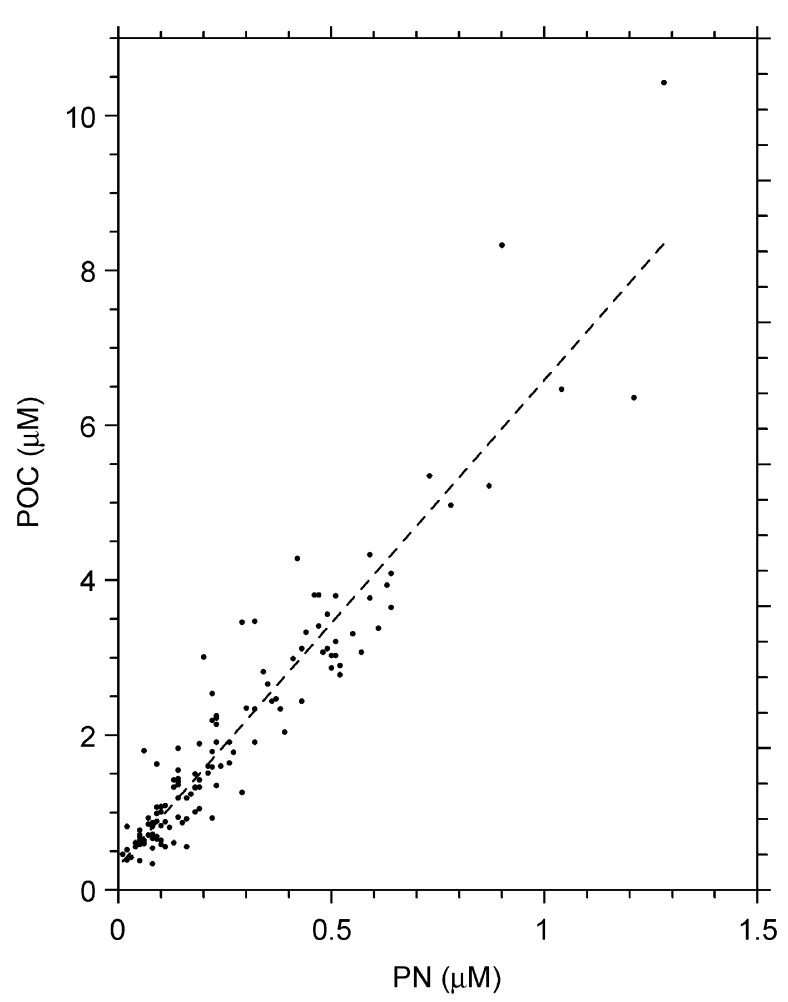

Fig. 5. Scatter plot of POC concentration vs. PN concentration obtained on the 10 cruises listed in Table 1. The line indicates the result of linear regression.

bounded by the two limits of $1.0(\mathrm{~g} \mathrm{Chl} / \mathrm{mol} \mathrm{N})$ and $2.5(\mathrm{~g} \mathrm{Chl} / \mathrm{mol} \mathrm{N})$. These ratios may be converted into $\mathrm{OC}_{\mathrm{Phy}} / \mathrm{Chl}$ ratio as follows:

$\mathrm{OC}_{\text {Phy }} / \mathrm{Chl}=R_{\mathrm{CN}} M_{\mathrm{C}} / R$,

where $R_{\mathrm{CN}}$ is the $C / N$ Redfield ratio (6.625) and $M_{\mathrm{C}}$ is the atomic weight of carbon. The corresponding $\mathrm{OC} / \mathrm{Chl}$ ratios of the upper and lower limits of $R$ are 79.5 and 31.8 , respectively.

In reality it is difficult to determine the values of the $\mathrm{OC}_{\text {Phy }} / \mathrm{Chl}$ ratio. Instead the values of $\mathrm{POC} /$ Chl- $a$ ratio are readily available. Since POC consists of OC in phytoplankton and detritus, it can be expressed as follows:

$[\mathrm{POC}]=[\mathrm{OC}]_{\mathrm{Phy}}+[\mathrm{OC}]_{\mathrm{D}}$,

where $[\mathrm{OC}]_{\text {Phy }}$ represents $\mathrm{OC}$ in phytoplankton cells and $[\mathrm{OC}]_{\mathrm{D}}$ represents $\mathrm{OC}$ in detritus. Then the $\mathrm{POC} / \mathrm{Chl}-a$ ratio may be expressed as follows:

$\mathrm{POC} / \mathrm{Chl}=[\mathrm{OC}]_{\mathrm{Phy}} /[\mathrm{Chl}-a]+[\mathrm{OC}]_{\mathrm{D}} /[\mathrm{Chl}-a]$

$$
\geqslant \mathrm{OC}_{\mathrm{Phy}} / \mathrm{Chl} \text {. }
$$

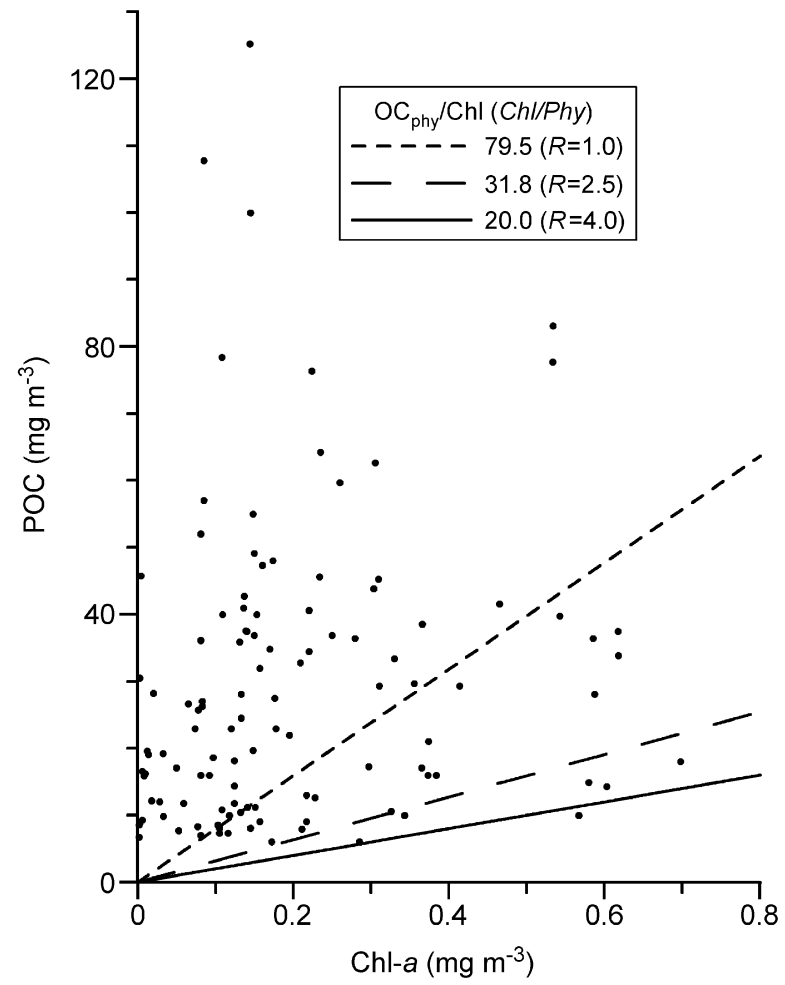

Fig. 6. Scatter plot of POC concentration vs. Chl- $a$ concentration obtained on the 10 cruises listed in Table 1. The lines indicate different $\mathrm{OC}_{\text {phy }} / \mathrm{Chl}-a$ ratios. The ratios in units of $\mathrm{g} / \mathrm{g}$ and the corresponding $R$-values in units of $\mathrm{g} \mathrm{Chl} / \mathrm{mol} \mathrm{N}$ are listed in the legend.

In other words, the $\mathrm{OC}_{\mathrm{Phy}} / \mathrm{Chl}$ ratio should be the lower limit of the $\mathrm{POC} / \mathrm{Chl}$ ratio.

The relationship between POC and Chl- $a$ observed on the 10 cruises is displayed in the scatter plot (Fig. 6). The lower bound of the observed distribution is close to the lower limit of the $\mathrm{OC}_{\mathrm{Phy}} /$ Chl ratio of 31.8 mentioned above, but a few data points fall below the presumed lower limit (Fig. 6). This discrepancy warrants a closer examination and further discussion.

The observed POC/Chl- $a$ ratio, which varies in a wide range, is plotted against depth for different seasons over the annual cycle (Fig. 7). The seasons are so defined that every season consists of 3 months with winter beginning in December. The distributions display a general pattern of a decreasing trend with depth in the surface layer and a reversed trend in the deeper water. It is noted that the increasing trend in the subsurface layer did occur in all seasons, though it is not shown in the plot for the fall season, because the reversal depth is quite deep (Fig. 7D). The observed POC/Chl values at 150 and $200 \mathrm{~m}$ for the 
(A)

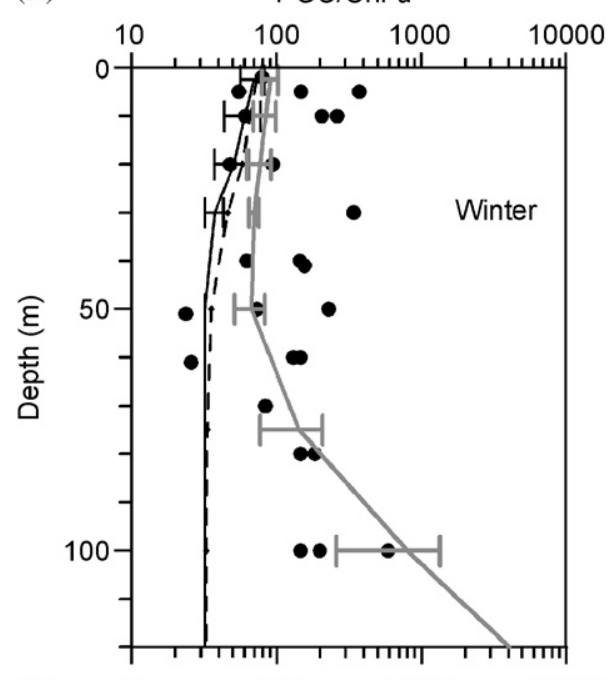

(C)

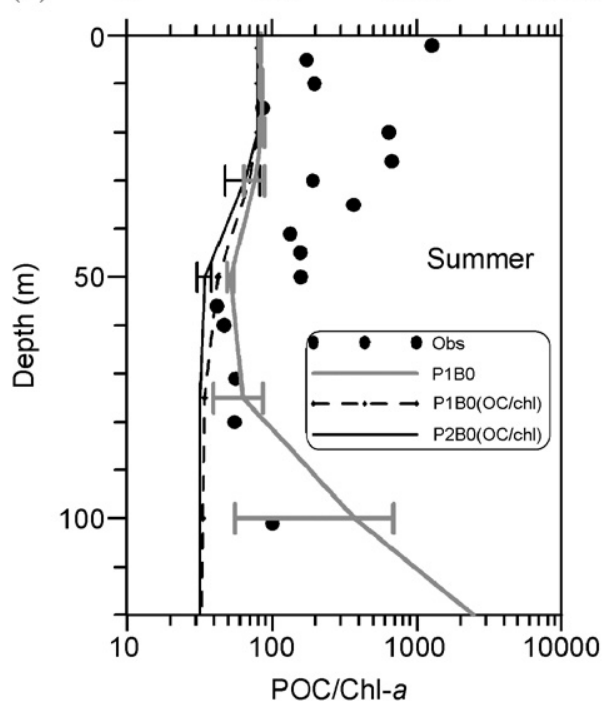

(B)

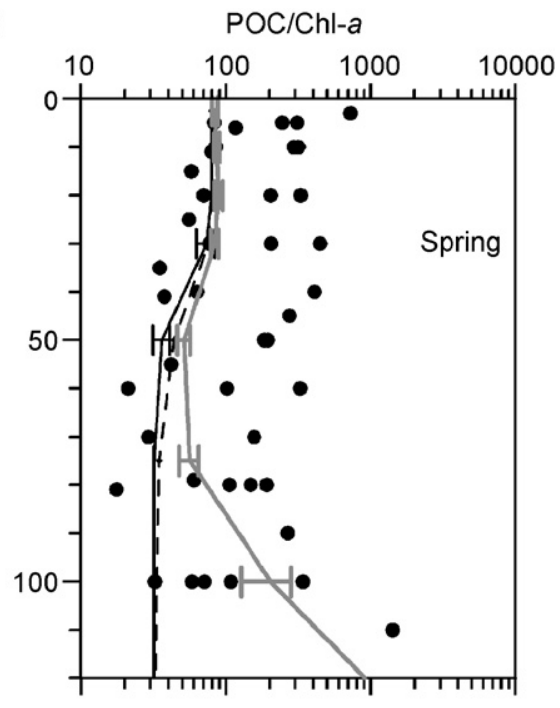

(D)

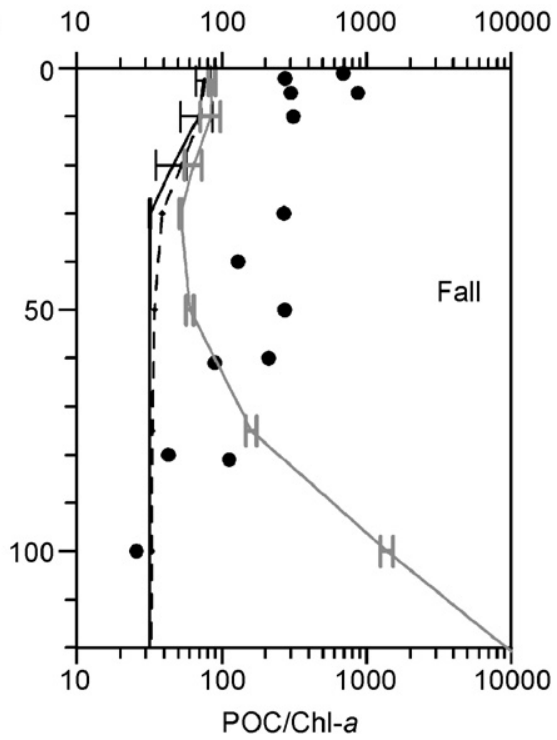

Fig. 7. Comparison between observed data and the modeled (Experiment P1B0) profile (gray line) of the POC/Chl- $a$ value (g/g) from the top $120 \mathrm{~m}$ at the SEATS Station for the four seasons. Also plotted are the modeled profiles of the $\mathrm{OC}_{\mathrm{Phy}} / \mathrm{Chl}$ ratio predicted by two different models indicated in the legend. The horizontal bars, which are shown for selected numerical experiments for the clarity of the figure, represent standard deviations of intra-seasonal variations predicted by the model.

fall season were 429 and 1980 (not shown), which were much higher than that (26) observed at $100 \mathrm{~m}$. The decreasing trend of $\mathrm{POC} / \mathrm{Chl}$ ratio with depth in the surface layer reflects the increasing $R$ value with decreasing light intensity. The reversed trend at greater depth beneath the euphotic zone is expected as the contribution of detritus to the POC pool increases below the euphotic zone, which is typically around $80-100 \mathrm{~m}$ (Tseng et al., 2005), while the contribution from phytoplankton decreases due to diminishing light intensity.
The distribution pattern mentioned above is well captured by the modeled POC/Chl profiles (Fig. 7). The modeled ratios represent the mean values of the nine grid points at and around the SEATS Station with the center at $115.8^{\circ} \mathrm{E}$ and $18^{\circ} \mathrm{N}$ averaged over the 3 months in each season. The standard deviations represent the intra-season variabilities. Also plotted are profiles of the modeled $\mathrm{OC}_{\mathrm{Phy}} / \mathrm{Chl}$ ratios, which should represent the lower limit of the POC/Chl values (Fig. 7). The modeled $\mathrm{OC}_{\mathrm{Phy}} / \mathrm{Chl}$ ratios are quite close to the lower bound of the 
observed distributions, but some data point's fall below the modeled $\mathrm{OC}_{\text {Phy }} / \mathrm{Chl}$ values. There is a strong seasonal difference in this disparity, which occurs mostly in spring and sparsely in winter, but almost never in summer and fall. In fact, most data points from summer and fall lie considerably above the modeled $\mathrm{OC}_{\mathrm{Phy}} / \mathrm{Chl}$ ratios. The seasonal contrasts could be attributed to changes in cellular fluorescence and composition of phytoplankton community (Liu et al., 2007). These authors observed that cellular fluorescence increases with depth in the top $100 \mathrm{~m}$ at the SEATS Station. Their estimated increase of chlorophyll amount per unit cell volume is 3.4-fold for Prochlorococcus and 2.1-fold for Synechococcus. This serves as direct evidence of increasing $R$ value or decreasing $\mathrm{OC}_{\mathrm{Phy}} /$ $\mathrm{Chl}$ ratio with depth. They found cellular fluorescence of picophytoplankton in the mixed layer higher in winter and spring than in other seasons. In addition, they also observed higher abundance of Synechococcus and picoeukaryotes in winter and spring with maxima in the subsurface layer. This could be attributed to the enhanced nutrient input to the euphotic zone as witnessed by the increase in mixed layer nutrients at the SEATS Station (Tseng et al., 2005). The nutrient transport was probably facilitated by a combination of localized upwelling, especially off northwestern Luzon (Shaw et al., 1996; Liu et al., 2002) and strengthened wind mixing (Tseng et al., 2005). The elevated nutrient concentration in the mixed layer favors higher $\mathrm{Chl} / \mathrm{Phy}$ ratio under low light conditions. These may contribute to the exceptionally low $\mathrm{POC} / \mathrm{Chl}$ ratios found in winter and spring. The occurrences of POC/Chl values below the modeled lower limits suggest that the actual enhancement of the Chl/Phy ratio under low light conditions could have been stronger than the condition assumed by the model. In other words, the upper limit of the $R$ value could be higher than 2.5 as adopted in the model (Doney et al., 1996). The scatter plot of POC vs. Chl- $a$ (Fig. 6) shows that the POC/Chl value could be as low as 20 , which corresponds to an $R$ value of 4.0. This is even higher than the value (3.0) recommended by Moore et al. (2002). We adopt an $R_{\mathrm{L}}$ value of 3.5 for this study.

\subsubsection{Effects of photo-adaptation on chlorophyll distribution}

Numerical experiments (Table 3) are performed to demonstrate the significance of the photoadaptation scheme on Chl- $a$ distribution and primary production and also to assess the effect of the increased upper limit of the $R$ value. Experiment $\mathrm{P} 1 \mathrm{~B} 0$ is the original case (Liu et al., 2002), which uses the original scheme of photo-adaptation with $R_{\mathrm{L}}$ set to 2.5. It serves as the basis for comparison. Experiment P0B0 removes the photo-adaptation scheme and uses a constant $R$ value of 1.59 (Fasham et al., 1990). Experiment P2B0 employs a higher $R_{\mathrm{L}}$ value of 3.5 .

The modeled profiles of Chl- $a$ from the three experiments are plotted alongside the observed values at SEATS for different seasons as defined earlier (Fig. 8). The observed vertical distributions of Chl- $a$ show surface Chl- $a$ concentrations less than $0.2 \mathrm{mg} \mathrm{m}^{-3}$ and a prominent subsurface maximum in all seasons except winter.

Results from Experiments P1B0 and P2B0 show similar trends in all seasons (Fig. 8). Both of them produce surface Chl- $a$ concentrations resembling the observed values. The modeled profiles also show prominent subsurface Chl- $a$ maxima in all seasons except winter, but the depths of the modeled maxima are all shallower than the observations. For winter the modeled profiles show broad peaks with maxima close to the surface (Fig. 8A). By contrast, Experiment P0B0 produces surface Chl- $a$ concentrations higher than observed values in all seasons except winter. For winter the modeled surface Chl- $a$ level agree with results of the other two models. Most of modeled Chl- $a$ profiles predicted by Experiment $\mathrm{P} 0 \mathrm{~B} 0$ show a rapid decrease with depth below the top $20 \mathrm{~m}$, indicating the failure of this model to generate any substantial subsurface chlorophyll maximum (SCM).

By comparison, the two models with a scheme for photo-adaptation, though unable to reproduce the depths of the subsurface chlorophyll maxima precisely, are able to generate the peak values in reasonable agreement with observations (Fig. 8B-D). For winter, the modeled values from these two experiments cover the observed ranges reasonably well in the top $30 \mathrm{~m}$, but fall below the observed ranges between depths of 30 and $80 \mathrm{~m}$ (Fig. 8A). It is noted that Experiment $\mathrm{P} 2 \mathrm{~B} 0$ generates stronger subsurface chlorophyll maxima in all seasons than Experiment P1B0. For spring (Fig. 8B), the depth of its modeled SCM is deeper than that from $\mathrm{P} 1 \mathrm{~B} 0$ and closer to the observed depths, but its surface Chl- $a$ concentrations are lower than those from P1B0.

It is clear that photo-adaptation is critical to the healthy development of SCM, which is a widespread phenomenon in the oligotrophic ocean (Furuya, 
(A)

(A)

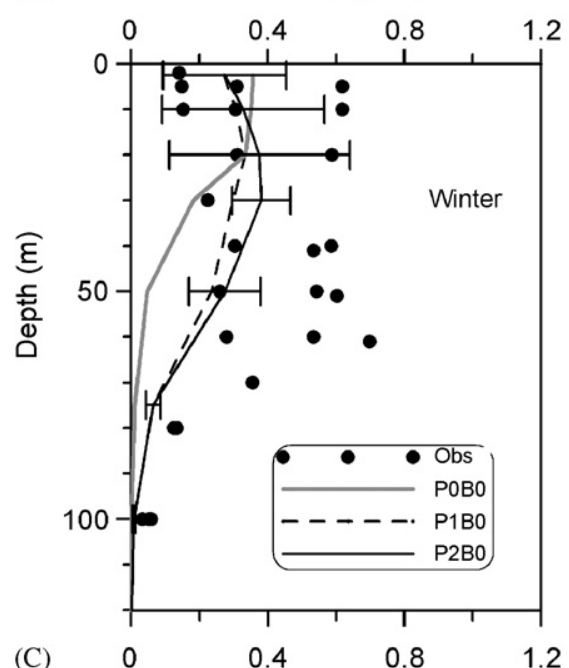

(C)

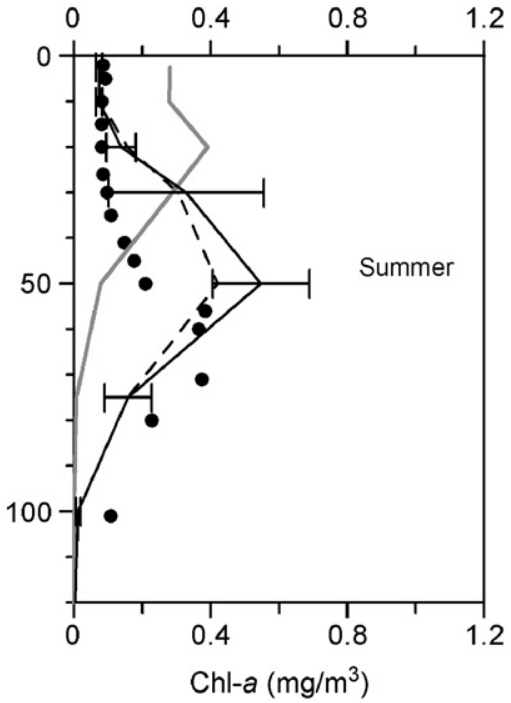

(B)

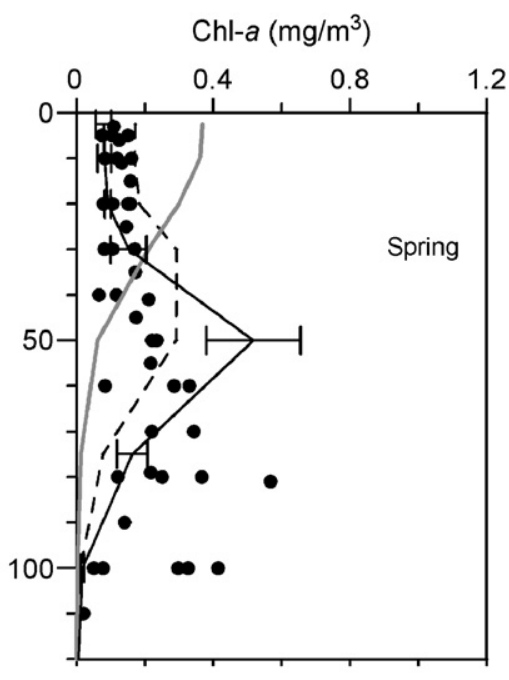

(D)

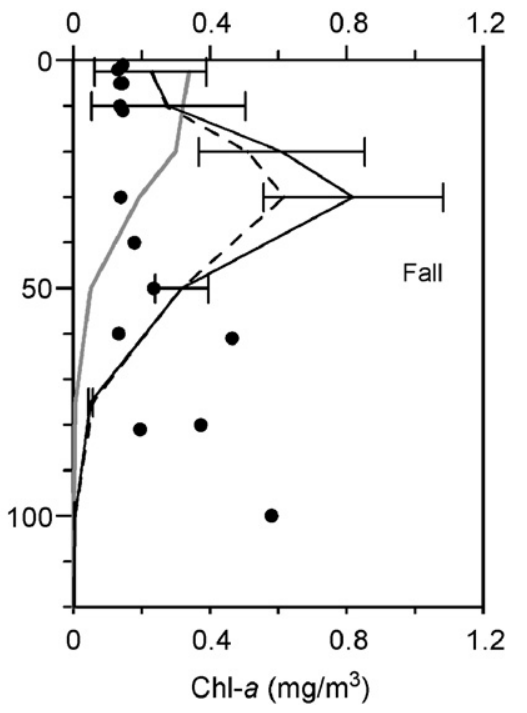

Fig. 8. The same as Fig. 7 except for Chl- $a$.

1990). Increase of the upper limit of the $R$ value under low light $\left(R_{\mathrm{L}}\right)$ from 2.5 to 3.5 helps to further enhance the SCM and bring the peak depth of the SCM closer to the observed depth. However, the improvement is not sufficient to account for the substantial concentration of Chl- $a$ observed in the deeper part of the euphotic zone. Further modification of both the physical and biogeochemical model is needed to improve the model performance in this aspect. More discussion on the causes of these deficiencies is given below.

It has been shown previously (Liu et al., 2002) that the predicted depth of the SCM is closely related to the predicted nitracline, which is usually too shallow as compared to the observations. The observed and modeled profiles of temperature, nitrate and Chl- $a$ at the SEATS Station for July are presented as an example (Fig. 9). The modeled temperatures are in agreement with the observed values in the top $10 \mathrm{~m}, 40-60 \mathrm{~m}$ and below $500 \mathrm{~m}$ (not shown), but too low for $10-40 \mathrm{~m}$ and too high for $60-500 \mathrm{~m}$. First we focus on the surface layer. The under-developed mixed layer predicted by the model is attributable to the wind forcing used for the model, which is the climatological monthly mean wind (Hellerman and Rosenstein, 1983). The monthly mean wind stress $(0.07 \mathrm{~Pa})$ is weaker than the actual wind stress observed in July 2000, which ranged from 0.003 to $0.477 \mathrm{~Pa}$ with a mean of $0.10 \pm 0.10 \mathrm{~Pa}$. Consequently, the modeled seasonal 
(A)

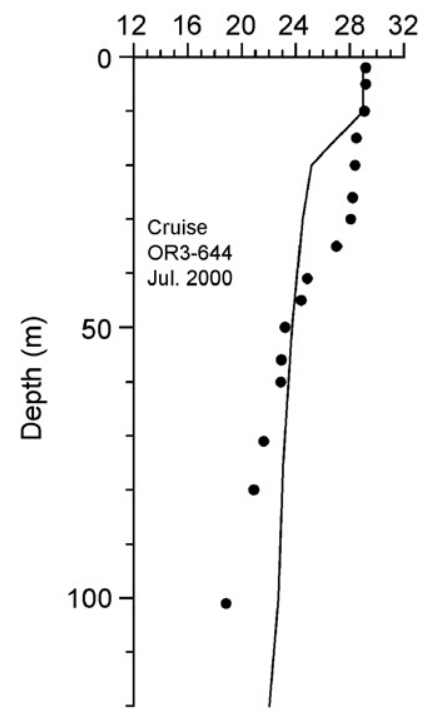

(B)

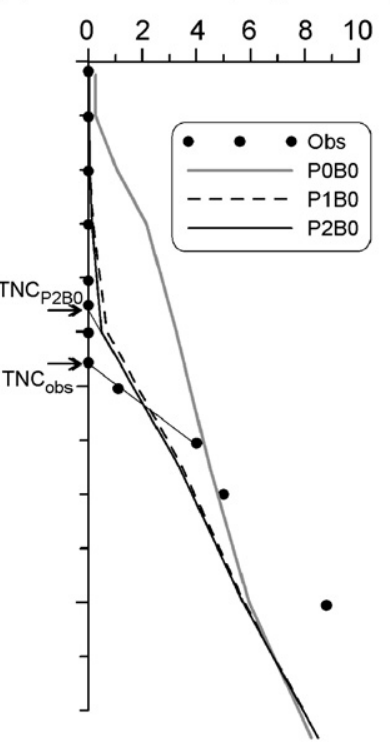

(C) Chl-a $\left(\mathrm{mg} / \mathrm{m}^{3}\right)$

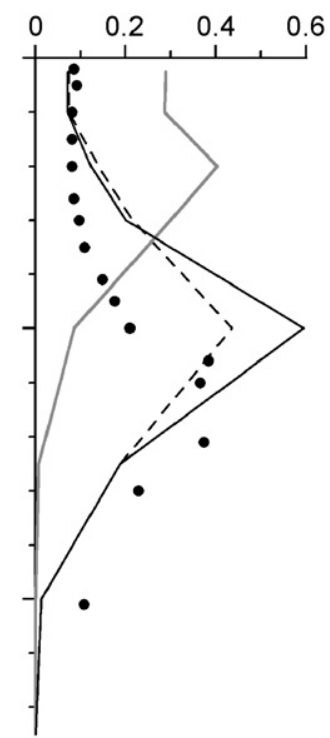

Fig. 9. Observed (dots) and modeled profiles (curves) of (A) temperature, (B) DIN and (C) Chl- $a$ at the SEATS Station for July. The observations were obtained in July 2000. The modeled temperature profiles from the two numerical experiments are identical. The arrows in panel (B) indicate the top of the nitracline (TNC) for the observed and the modeled (P2B0) DIN profiles (see text).

thermocline is usually too shallow, and the subsurface water, which is cooler and has more nutrients, gets too close to the surface in the model results. This makes the modeled nitracline shallower than the observed one (Fig. 9B). The observed nitracline was deeper than the thermocline; so are the modeled nitraclines as predicted by Experiments P1B0 and $\mathrm{P} 2 \mathrm{~B} 0$. By contrast, the nitracline predicted by Experiment P0B0 is very close to the modeled thermocline. Deepening of the nitracline with respect to the thermocline is caused by nutrient uptake. The very weak deepening of the nitracline without photo-adaptation indicates its inefficient nutrient uptake under low light conditions in the subsurface water. The upper bound of the observed SCM was very close to the top of the nitracline (Fig. 9B), which is defined as the depth where the segment of the DIN profile with fast increasing concentration would intercept the depth axis in a backward extension (Tseng et al., 2005). Experiments $\mathrm{P} 1 \mathrm{~B} 0$ and $\mathrm{P} 2 \mathrm{~B} 0$ also demonstrate similar relationship between the SCM and the nitracline. The close match of the onset of the SCM and the top of the nitracline is a result of the interaction between the physical process for nutrient supply and the biological process of nutrient uptake.

The mismatch between the modeled and the observed temperature profile in the subsurface layer deserves consideration. Observations from mooring at the SEATS Station (Yang et al., 2004) have revealed that the near-surface temperature variations at the SEATS site are dominated by monsoonenhanced seasonal changes, while the intra-seasonal fluctuations with a period around 100 day are prominent in the ocean interior deeper than $100 \mathrm{~m}$. Compared to the temperature profile observed in January 2000 (Fig. 3A), the temperatures observed in July (Fig. 4A) were considerably higher in the top $40 \mathrm{~m}$ but became lower than those observed at the same depths in the subsurface layer in January. The de-coupled temperature variation between surface and subsurface layers is the evidence of the intraseasonal oscillation. How such interior oscillation may affect the biogeochemical processes in the euphotic zone warrants further investigation but is beyond the scope of this study, which focuses on the monsoonal forcing.

The discrepancies in the modeled temperature profiles from observations lead to discrepancies in modeled DIN profiles. The overestimated modeled temperatures in the subsurface water correspond to underestimated DIN concentrations at depths greater than $70 \mathrm{~m}$ (Fig. 9B). However, on a longer time scale the modeled DIN distribution agrees well with the median values of the observed ranges in the subsurface water $(70-250 \mathrm{~m})$ in the SCS proper 
(Liu et al., 2002). This indicates the occasional DIN deficiency as displayed in Fig. 9B not a viable cause for the persistent deficiency in the modeled deep Chl- $a$ stock (Figs. 8 and 9C). We have tried to optimize the other photo-adaptation parameter in Eq. (4), namely, $E_{\mathrm{PA}}$, which showed little improvement. For further improvement of the phytoplankton growth under low-light high-nutrient conditions, more acclimation process, such as optimizing the $\mathrm{C} / \mathrm{N} / \mathrm{P}$ ratio (Geider et al., 1998; Christian, 2005; Pahlow, 2005), may be considered.

\subsubsection{Effects of photo-adaptation on primary production}

The modeled IPP values at the SEATS Station from different numerical experiments are compared with observed values (Chen, 2005) in a plot of monthly mean values throughout the year (Fig. 10). It is interesting that all modeled IPP values converge toward the observed value in summer. Aside from summer, Experiment P0B0 underestimates IPP values throughout the year. Because the physical processes are identical in these experiments, gross underestimation indicates that the lack of photoadaptation makes the ecosystem inefficient in utilizing available nutrients in the euphotic zone. Without photo-adaptation, the modeled annual IPP is lower than that predicted by the original model by $39 \%$. Although the models with photo-adaptation fail to reproduce the higher end of the observed IPP

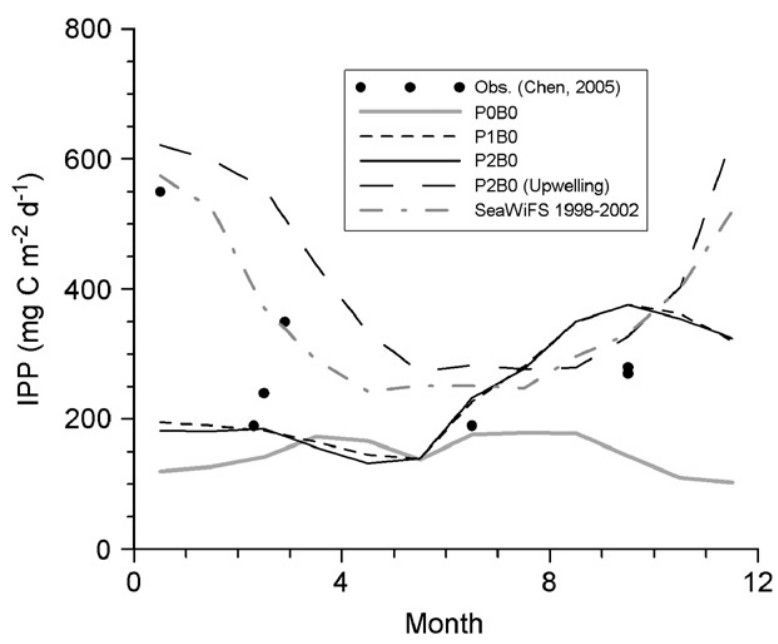

Fig. 10. Comparison between the observed data and the timeseries curves of the modeled IPP value $\left(\mathrm{mg} \mathrm{Cm}^{-2} \mathrm{~d}^{-1}\right)$ at the SEATS Station. Also plotted are the time-series curves of the modeled IPP in the upwelling region off northwestern Luzon and the SeaWiFS data-derived IPP value in the SEATS region (see text). values in winter and spring, they are able to catch the lower end of the observed values in spring and slightly overestimate the IPP in fall. It is noted that the increase of the $R_{\mathrm{L}}$ value does little to enhance overall phytoplankton growth as indicated by the nearly identical IPP values generated by P1B0 and $\mathrm{P} 2 \mathrm{~B} 0$. However, it is to be shown later that primary productivity is indeed enhanced in areas where the nutrient supply is rich.

The failure of the models to catch the high IPP in winter and spring deserves attention. It has been recognized that the model of Liu et al. (2002) produces localized phytoplankton blooms in all the upwelling areas, including the one off northwest Luzon, whereas ocean color images indicate that the bloom tends to spread northwestward (Liu et al., 2002). To illustrate this point, we plot the mean monthly IPP values derived from SeaWiFS chlorophyll concentrations at sea surface using the VGPM algorithm of Behrenfeld and Falkowski (1997). The monthly mean values are averaged over the area of $1^{\circ} \times 1^{\circ}$ centered at the SEATS Station and over the period from 1998 to 2002. The SeaWiFS data derived IPP values are quite high for winter and spring, indicating westward dispersion of high Chl- $a$ patches from the upwelling zone northwest of Luzon to the SEATS site (Chen et al., 2006).

Such activities are probably facilitated by eddy shedding during the intrusion of the Kuroshio into the SCS ( $\mathrm{Wu}$ and Chiang, 2007), which prevails under the northeast monsoon (Shaw, 1991; Xue et al., 2004). The wide range of IPP values (195-350 $\mathrm{mg} \mathrm{C} \mathrm{m}^{-2} \mathrm{~d}^{-1}$ ) observed in March (Chen, 2005 ) indicates different states with or without eddy activities in the vicinity of the SEATS Station (Fig. 10). Our model, which is too coarse in horizontal resolution to permit eddy shedding, can only simulate the state without eddy activities in the vicinity of the SEATS Station. The biological activities in the high Chl- $a$ patches should resemble those of the upwelling area. The modeled IPP in the upwelling area (Liu et al., 2002), $117-120^{\circ} \mathrm{E}$ and $17.5-18.5^{\circ} \mathrm{N}$, which is directly to the east of the SEATS Station, show a trend very similar to the SeaWiFS derived IPP values, but the magnitudes are considerably higher in winter and spring (Fig. 10). In other words, the model is capable of reproducing the high IPP values as observed but the spatial distribution is inaccurate due to the coarse resolution of the model. It is shown later that the modeled IPP values are comparable to the averages 
of observed values on the basin-wide scale. It is warranted to adopt a hydrodynamic model with finer horizontal resolution, such as the one developed by $\mathrm{Wu}$ and Chiang (2007), for better biogeochemical modeling of the SCS.

\subsection{Benthic-pelagic coupling}

\subsubsection{Primary productivity in the Gulf of Thailand}

In the western half of the Gulf of Thailand and the adjacent area along the east coast of the Malay Peninsula, the IPP values observed on the two cruises during the September-October period in 1995 (Musikasung et al., 1997) ranged between 200 and $610 \mathrm{mg} \mathrm{Cm}^{-2} \mathrm{~d}^{-1}$ (Fig. 11A) with most values between 200 and $500 \mathrm{mg} \mathrm{Cm}^{-2} \mathrm{~d}^{-1}$. The mean value is $367 \pm 97 \mathrm{mg} \mathrm{C} \mathrm{m}^{-2} \mathrm{~d}^{-1}$. The upper Gulf was the most productive probably due to the riverine discharge of nutrients from the Chao Phraya River, which discharges to the head of the Gulf (Liu et al., 2006). Another patch of relatively high primary productivity occurred in the lower Gulf and the zone around the Gulf mouth just south of the Mekong River mouth. This could be due to the influence of the Mekong River runoff, which is on average 10 times the discharge from the Chao Phraya River and is known to influence the Gulf (Liu et al., 2006).

The distribution of primary production predicted by the original coupled physical-biogeochemical model of Liu et al. (2002), namely, Experiment P1B0 (Table 3), is shown as Fig. 11B. The model results represent the averages between the monthly results for September and October in order to match the observational period. It is noted that the model results extend southward to $4^{\circ} \mathrm{N}$ in Fig. 11, though the model domain extends to $2^{\circ} \mathrm{N}$. The lower part of the model results are truncated, because the area is too close to the southern boundary and the modeled IPP may be too strongly affected by the boundary conditions. Despite the truncation, the model results reproduce the observed major features. The upper Gulf is more productive, while a patch of relatively high primary productivity occurs around the mouth of the Gulf. However, the level of the predicted primary production is only around $100 \mathrm{mg} \mathrm{C} \mathrm{m}^{-2} \mathrm{~d}^{-1}$, which is much too low as compared to the observations. For a direct comparison, the observed and the modeled values are averaged separately over the area of the intercept of the two domains. The observed mean is
$371 \mathrm{mg} \mathrm{C} \mathrm{m}^{-2} \mathrm{~d}^{-1}$, while the modeled mean is only $90 \mathrm{mg} \mathrm{C} \mathrm{m}^{-2} \mathrm{~d}^{-1}$.

The gross underestimation of primary production in the Gulf by the model could be attributed to various reasons. The major factors controlling primary production include the ecosystem model, light and DIN. The reasonable model skill in predicting IPP for the SEATS Station precludes the ecosystem model as the main culprit. The irradiance values of incidental light are similar for the Gulf and the SEATS Station. This leaves the nutrient availability as the most likely culprit. The nutrient supply to the Gulf may come from external as well as internal sources. The external sources include river runoffs and on-welling of nutrient-rich subsurface water from the SCS proper. The river runoffs are included as boundary conditions in the model (Liu et al., 2002). The rather limited runoff of the Chao Phraya River $\left(30 \mathrm{~km}^{3} \mathrm{a}^{-1}\right)$ brings an estimated flux of DIN $\left(1.8 \mathrm{Gmola}^{-1}\right)$ to the Gulf (Liu et al., 2006), which may account for less than $1 \%$ of required DIN for primary production based on the observed values of IPP. The much bigger Mekong River runoff, which disperses mainly to the SCS proper, may provide significant but not dominant nutrient supply to the Gulf. Nutrient input to the Gulf from on-welling of offshore subsurface water is probably the major external source similar to most coastal seas (Wollast, 1993), but it cannot be the dominant source, because the recessed geometry of the Gulf and the very low salinity in the Gulf (Liu et al., 2006) pose a strong potential barrier for upwelling. Hence, the main nutrient supply for the Gulf should be internal nutrient regeneration.

Nutrient regeneration may occur in the watercolumn or the sediments. Water-column regeneration is already embedded in the ecosystem model, but the benthic regeneration in the sediments has been neglected in the original model (Liu et al., 2002). Therefore, the reason for the under estimation of primary production in the Gulf is most likely the lack of benthic regeneration of nutrients in the model. Numerical experiments have been carried out to check this assumption.

\subsubsection{Effects of benthic processes in the Gulf of Thailand}

According to the numerical experiments, benthic processes influence the primary productivity in the Gulf of Thailand very strongly and also that of the 

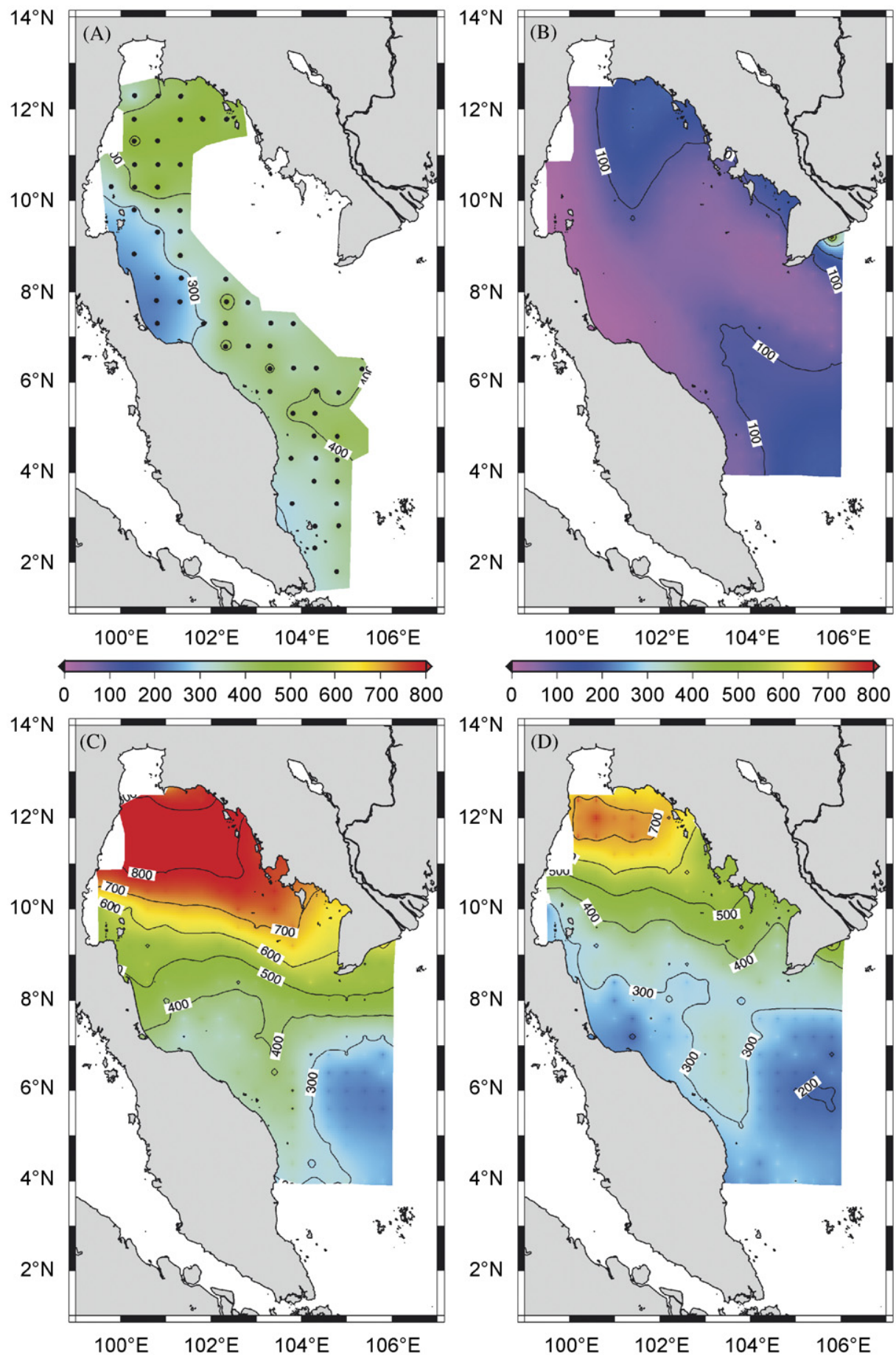

0100200300400500600700800

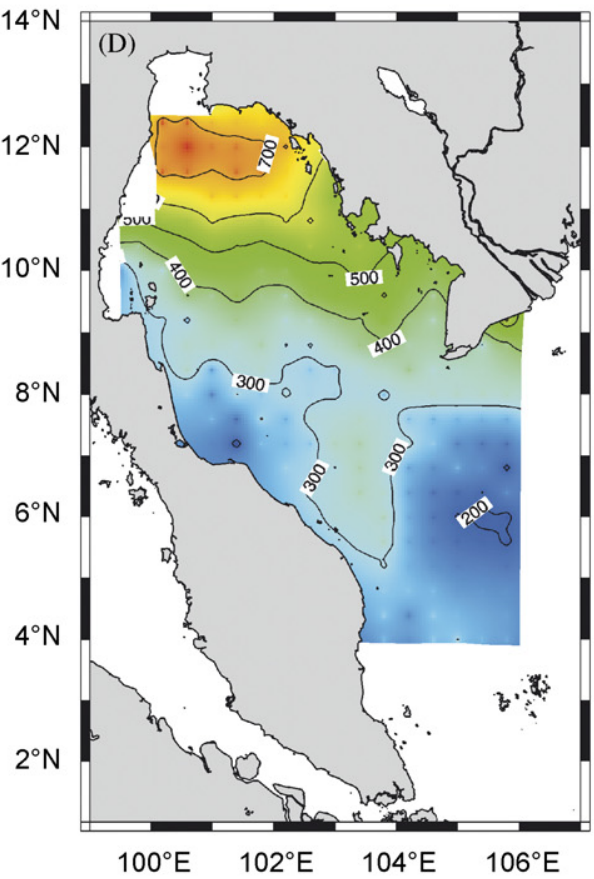

Fig. 11. Distribution of IPP $\left(\mathrm{mg} \mathrm{C} \mathrm{m}^{-2} \mathrm{~d}^{-1}\right)$ in the Gulf of Thailand in September-October. (A) Observations in 1995. (B) Model results of P1B0. (C) Model results of P1B1. (D) Model results of P1B2.

SCS as a whole, though the influence is less in the basin area than in the shelves. Details are elaborated below as revealed by Experiments P1B1 and P1B2 (Table 3).
In Experiment $\mathrm{P} 1 \mathrm{~B} 1$, the benthic regeneration is turned on with the $f_{\mathrm{N}}$ value set to 1.0 (Table 3 ), which means all of the particulate organic nitrogen (detritus) that hits the bottom is turned into DIN. 
The resultant primary production (Fig. 11C) is much enhanced over the original model, namely P1B0 (Fig. 11B). As before, the distribution of the modeled primary production (Fig. 11C) represents the average of the monthly conditions in September and October. The modeled primary production in the upper Gulf is so strongly enhanced that the predicted value $\left(>800 \mathrm{mg} \mathrm{C} \mathrm{m}^{-2} \mathrm{~d}^{-1}\right)$ is twice as high as the observed $\left(\sim 400 \mathrm{mg} \mathrm{C} \mathrm{m}^{-2} \mathrm{~d}^{-1}\right)$. The region of high primary productivity extends the length of the Gulf, decreasing to the south. Near the mouth of the Gulf, the modeled values resemble those of the observed values. Averaging of the modeled values over the area overlapping with the observational domain yields a value of $518 \mathrm{mg} \mathrm{C} \mathrm{m}^{-2} \mathrm{~d}^{-1}$, which is much closer to the observed value than that from the original model but still off the mark by almost $40 \%$.

In Experiment P1B2, the $f_{\mathrm{N}}$ value is set to 0.86 as that adopted in the recent model of the Mid Atlantic Bight (Fennel et al., 2006). This means that $14 \%$ of the particulate organic nitrogen that hits the bottom is lost to denitrification. The enhancement of the primary production is considerably subdued as compared to P1B1. The upper Gulf is still highly productive with the maximum primary production value exceeding $700 \mathrm{mg} \mathrm{C} \mathrm{m}^{-2} \mathrm{~d}^{-1}$. Compared to the observed values ranging mostly between 350 and $610 \mathrm{mg} \mathrm{C} \mathrm{m}^{-2} \mathrm{~d}^{-1}$ in the upper Gulf north of $10^{\circ} \mathrm{N}$, the model results are higher by about $100 \mathrm{mg} \mathrm{C} \mathrm{m}^{-2} \mathrm{~d}^{-1}$. The model successfully reproduces the relatively low primary productivity along the western coast of the Gulf. It also predicts a patch of relatively high primary production around $300 \mathrm{mg} \mathrm{C} \mathrm{m}^{-2} \mathrm{~d}^{-1}$ at the mouth of the Gulf, which is similar to the observed values, but the area of this patch is smaller than the observed patch. Averaging of the modeled values over the area overlapping with the observational domain yields a value of $399 \mathrm{mg} \mathrm{C} \mathrm{m}^{-2} \mathrm{~d}^{-1}$, which is very close to the average of the observed values.

The enhancement of primary production predicted by Experiments $\mathrm{P} 1 \mathrm{~B} 1$ and $\mathrm{P} 1 \mathrm{~B} 2$ is attributed to the benthic regeneration of nutrients in the Gulf, which strongly alters the nutrient distribution in the water column. Fig. 12 displays the average condition of the modeled DIN distributions in September and October along $102^{\circ} \mathrm{E}$ longitude in the Gulf. Without nutrient regeneration, the Gulf water is depleted in DIN to levels below $0.7 \mu \mathrm{M}$ throughout the Gulf (Fig. 12A). With the full strength of nutrient regeneration, the DIN level increases substantially with the surface values between 0.4 and $6.5 \mu \mathrm{M}$ and the bottom values between 8.5 and $16 \mu \mathrm{M}$ (Fig. 12B). With benthic regeneration as well as a $14 \%$ removal by denitrification, the DIN level in the surface water drops to $0.4-2.5 \mu \mathrm{M}$, while the bottom concentration drops to $5.5-9.5 \mu \mathrm{M}$ (Fig. 12C). The nutrient data from the World Ocean Atlas (Conkright et al., 1994) provide a reference for comparison with different modeled profiles as displayed in Fig. 13. The modeled DIN profiles are computed by interpolating the modeled monthly DIN output to the location of the gridded data, namely, $9.5^{\circ} \mathrm{N}$ and $101.5^{\circ} \mathrm{E}$, and averaging over the 1 -year period. None of the modeled outputs match exactly the observed profile, but the profile predicted by $\mathrm{P} 1 \mathrm{~B} 2$ is closest to the observed one.

All of the modeled distributions of DIN in the Gulf show a striking nutrient gradient with the most enriched nutrients in the upper Gulf (Fig. 12). Even the one without benthic nutrient regeneration predicts such a gradient in the surface layer. The nutrient gradient reflects the riverine discharge of nutrients in the upper Gulf (Chongprasith and Srinetr, 1998). These authors reported that the DIN concentration ranged between 0.7 and $2.9 \mu \mathrm{M}$ in the surface water of the upper Gulf and decreased to $0.3 \mu \mathrm{M}$ in the lower Gulf. Again the DIN distribution predicted by $\mathrm{P} 1 \mathrm{~B} 2$ best fits the observations. It has been reported that the nitrate concentration in the bottom water may reach $10 \mu \mathrm{M}$ or higher (Liu et al., 2006). The scenario predicted by P1B2 fits these descriptions reasonably well.

The much-enhanced primary production in the upper Gulf and the much-enriched DIN concentrations in the bottom water in the same region predicted by Experiments $\mathrm{P} 1 \mathrm{~B} 1$ and $\mathrm{P} 1 \mathrm{~B} 2$ indicate nutrient trapping, which results from a relatively long residence time for the Gulf water. Water renewal in the Gulf is through exchange with the open SCS driven by tidal currents and circulation driven mainly by the alternating monsoons. The precise flush time of the Gulf is not known, but a persistent salinity gradient between the coastal water and the offshore water in the inner Gulf, even in dry seasons, suggests that the residence time of the inner shelf is at least 2-3 months (Wattayakorn et al., 1998). The modeled transports of water exchange between the Gulf and the SCS proper over the Gulf sill are about $0.9 \mathrm{~Sv}$ in both ways on average. The mean residence time of the Gulf water based on these estimates is about 5 months, which does not contradict the above estimate. However, 

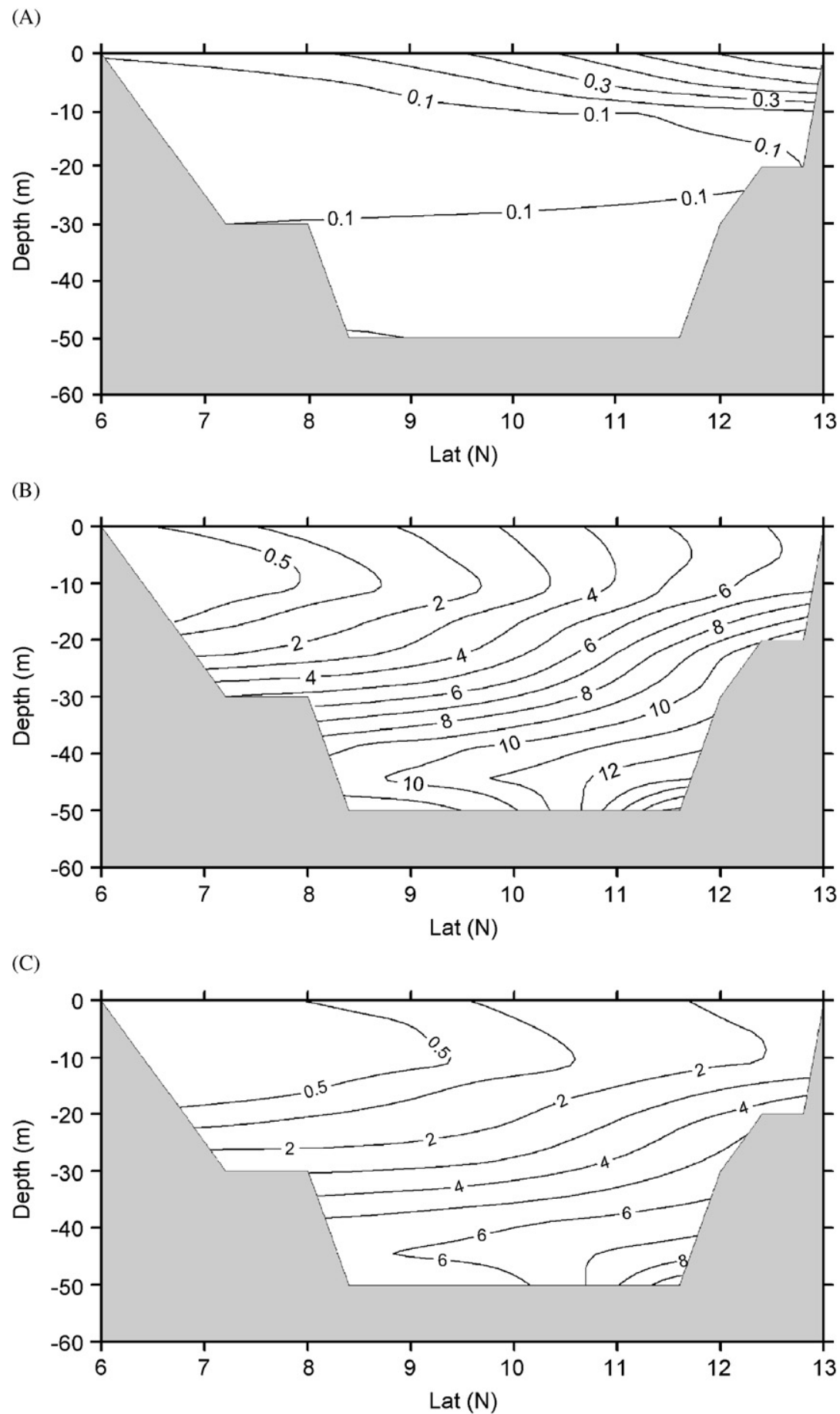

Fig. 12. Modeled distribution of DIN $(\mu \mathrm{M})$ in the Gulf of Thailand along $102^{\circ}$ E. (A) P1B0. (B) P1B1. (C) P1B2.

because the model does not include tidal forcing, the modeled water exchange could be less efficient than the actual situation due to the lack of tidal mixing. It cannot be ruled out that the less efficient water exchange of the model may cause over-trapping of nutrients in the Gulf, but the fairly large size of the Gulf may limit the extent of water exchange induced by tidal mixing. Nevertheless, a more precise simulation of nutrient cycling in the Gulf may need a more realistic hydrodynamic model. 


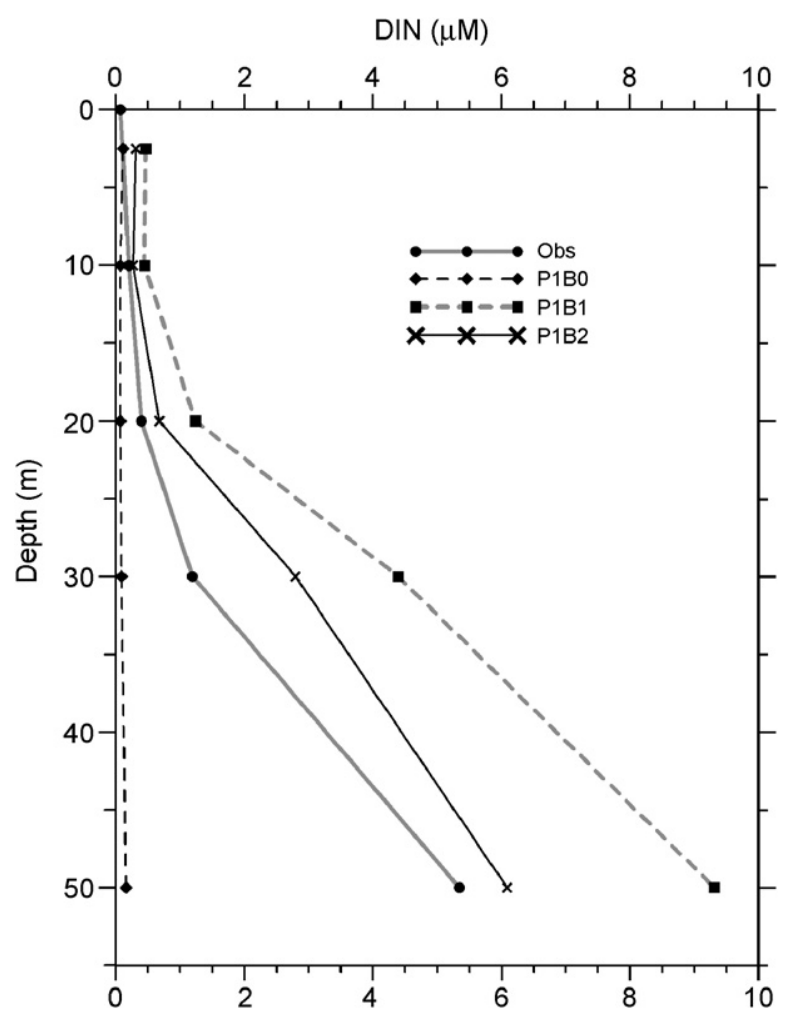

Fig. 13. Observed (Conkright et al., 1994) and modeled DIN $(\mu \mathrm{M})$ profiles in the Gulf of Thailand at $9.5^{\circ} \mathrm{N}$ and $101.5^{\circ} \mathrm{E}$.

\subsubsection{Benthic nutrient regeneration and denitrification}

As demonstrated above, Experiment P1B2 with coupled nitrification-denitrification is capable of generating distributions of primary productivity and DIN in the Gulf of Thailand in reasonable agreement with observations. We would like to explore how the benthic processes may affect biogeochemistry in the SCS as a whole. In this section, we present the effect on DIN distribution and provide an estimation of denitrification fluxes in the SCS. The effect on primary productivity in the entire SCS basin is to be discussed later.

Because the top $30 \mathrm{~m}$ is the most productive layer in the SCS proper (Chen, 2005), we present the DIN distribution at $30 \mathrm{~m}$ (Fig. 14). It is revealed in the vertical section of DIN distribution in the Gulf of Thailand (Fig. 12) that the surface water is enriched in DIN due to riverine discharge but the direct influence of the river plume appears only in the top 10-20 m. Therefore, the DIN distribution at $30 \mathrm{~m}$ properly reflects the effect of the benthic processes.
The annual average distribution of DIN at $30 \mathrm{~m}$ depth predicted by P1B0 (Fig. 14A) shows very low DIN concentrations near the coast on the shelves and slightly elevated DIN concentrations $(1-2 \mu \mathrm{M})$ in the central basin. By contrast, P1B2 (Fig. 14B) predicts much higher DIN concentrations in the coastal zone on the shelves, whereas the DIN concentrations in the central basin remain at the same level. A closer examination reveals that P1B2 produces a slightly larger area with DIN concentrations above $2 \mu \mathrm{M}$. In the coastal zone, DIN concentrations are raised to $4 \mu \mathrm{M}$ or higher in the upper Gulf of Thailand due to nutrient trapping as mentioned before. An even stronger enrichment with highest DIN concentrations reaching $8 \mu \mathrm{M}$ or higher occurs in the Bay of Tokin, while the enrichment is quite limited in the coastal zone around the Pearl River mouth, even though the riverine discharge of nutrients from the Pearl River is substantial. The nutrient trapping effect is apparently inversely related to the turnover rate of the water body. Assuming a river plume region of about $200 \mathrm{~km}$ on each side of the river mouth with a mean width of $100 \mathrm{~km}$ extending seaward from the coast, we found a modeled residence time of 2.4 months for the shelf water within the river plume. This is considerably shorter than that of the Gulf of Thailand; yet it is probably the upper limit because of the lack of tidal mixing in the model. The rather fast turn over of the shelf water off the Pearl River mouth is responsible for the less pronounced nutrient trapping effect.

It is easier to see the difference between model results by subtracting the modeled values of one experiment from those of another. The effects of the benthic processes are best revealed by subtracting the P1B0 values from the P1B2 values (Fig. 15A). It is expected that the more pronounced effect of the benthic processes occur on the shelves. However, non-negligible enrichment of DIN also spreads beyond the shelf break but only restricted to the southwestern part of the basin. Although the increase of DIN at $30 \mathrm{~m}$ depth over the deeper part of the SCS is limited, the increase is significant as compared to the half saturation concentration of nitrate uptake, which is $0.5 \mu \mathrm{M}$ for small phytoplankton (Moore et al., 2002). Because the phytoplankton in the SCS is dominated by organisms smaller than $3 \mu \mathrm{m}$ (Chen, 2005; Liu et al., 2007), the $0.2-0.5 \mu \mathrm{M}$ increase of DIN in the oligotrophic upper euphotic zone is likely to enhance phytoplankton growth substantially. 

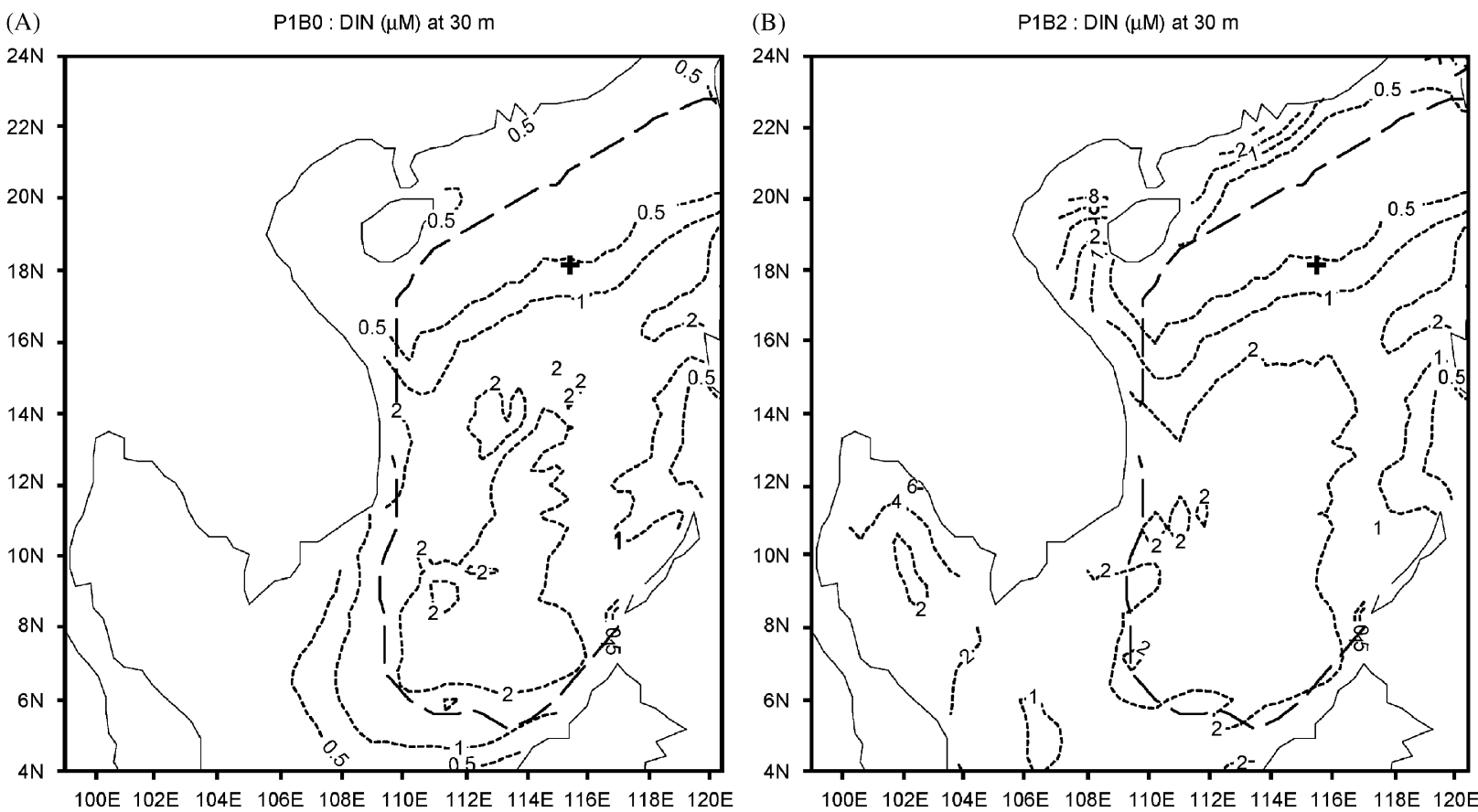

Fig. 14. Modeled distribution of DIN $(\mu \mathrm{M})$ at $30 \mathrm{~m}$ depth in the SCS. The cross indicates the locality of the SEATS Station and the longdashed curve is the $200 \mathrm{~m}$ isobath. (A) P1B0. (B) P1B2.
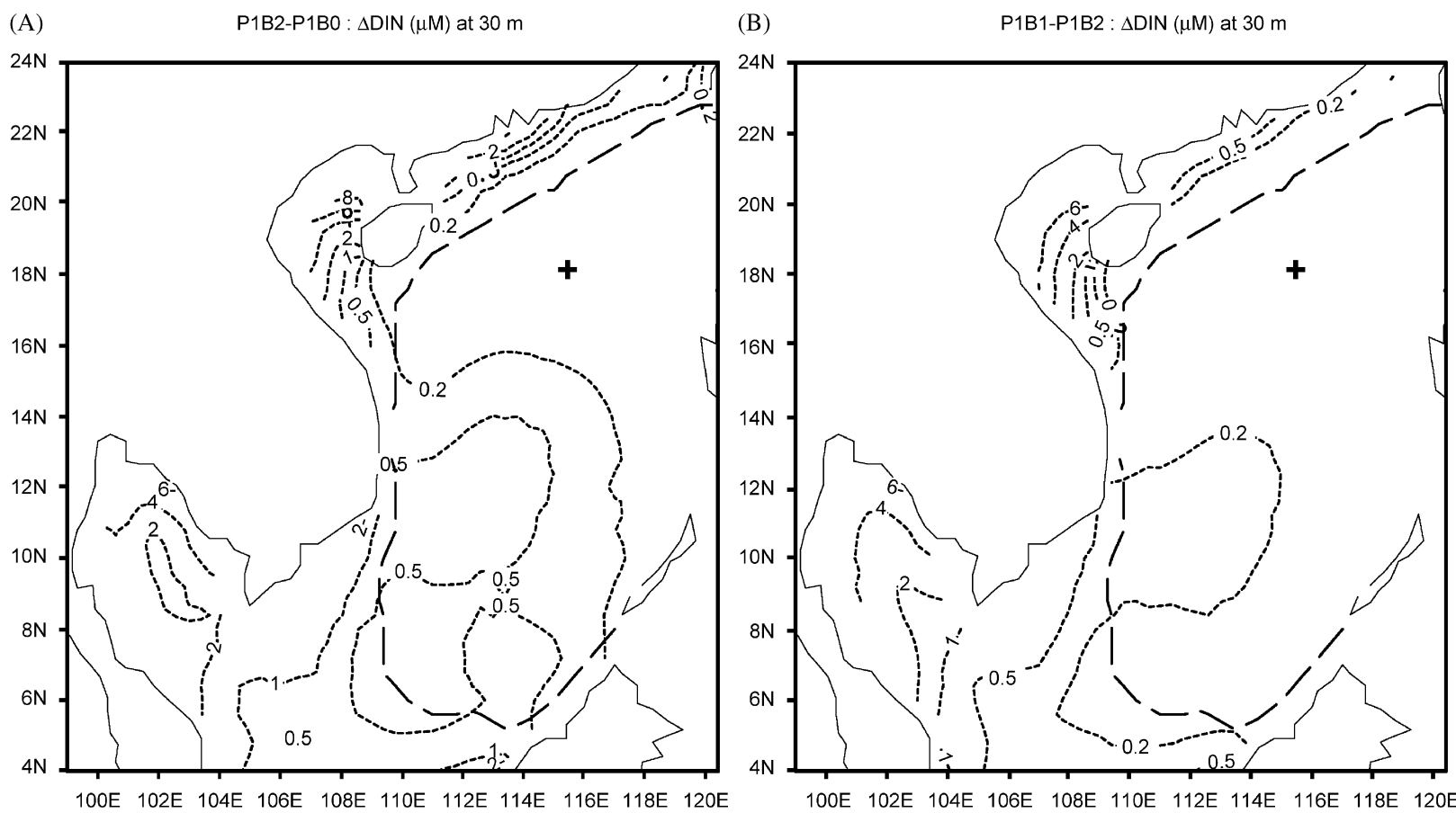

Fig. 15. The same as Fig. 14 except for the difference of modeled DIN $(\mu \mathrm{M})$ at $30 \mathrm{~m}$ depth from different experiments. (A) P1B2-P1B0. (B) P1B1-P1B2. 
About half of the surface layer over the deep basin is affected by the lateral spreading of regenerated nutrients from the shelf sediments. The Gulf of Thailand appears to be an important source of nutrients, but the spreading of DIN from the shelf does not occur in the northeastern basin of the SCS. The lack of nutrient repletion in the northern SCS basin probably reflects the strong dilution effect incurred by the intrusion of the nutrient-depleted Kuroshio water (Shaw, 1991). The effect of the increased DIN on primary productivity is presented as the difference by subtracting the average IPP distribution produced by Experiment P1B0 from that of Experiment P1B2 (Fig. 16A). The primary productivity is not only enhanced in the shelf region but also in the central basin. The distribution of the IPP increase displays a pattern (Fig. 16A) resembling that of the DIN increase (Fig. 15A).

Compared to the results of $\mathrm{P} 1 \mathrm{~B} 2$, the nutrient enhancement of P1B1, which assumed the full nutrient regeneration in the benthic layer, is considerably stronger as indicated by the average difference in DIN distribution at $30 \mathrm{~m}$ depth (Fig. 15B). The average DIN concentrations at $30 \mathrm{~m}$ depth in the inner shelf predicted by $\mathrm{P} 1 \mathrm{~B} 1$ are $25-100 \%$ higher than those predicted by P1B2. In other words, it is denitrification that subdues nutrient trapping in the inner shelf. The benthic denitrification rate is to be discussed later.

It is noted that the benthic nutrient regeneration process is more complicated than hypothesized here. The overly enhanced nutrient accumulation in the upper Gulf could be partially attributed to the instant nutrient regeneration assumed by the model. A more sophisticated benthic model with appropriate consideration of diagenetic processes (Soetaert et al., 2000) may improve the nutrient distribution in the Gulf.

\subsection{Combined effects}

A numerical experiment, designated as $\mathrm{P} 2 \mathrm{~B} 2$, was conducted to investigate the combined effect of the enhanced photo-adaptation and the benthic processes (Table 3). We first present the effect on primary productivity and demonstrate the adequacy of the new improved model. Then we use the new model to assess the total primary production and denitrification in the SCS.

\subsubsection{Effects on primary production}

It has been shown for the SEATS Station that the strengthened photo-adaptation enhances the Chl- $a$ concentration in the lower part of the euphotic zone, but makes little change on IPP. The near

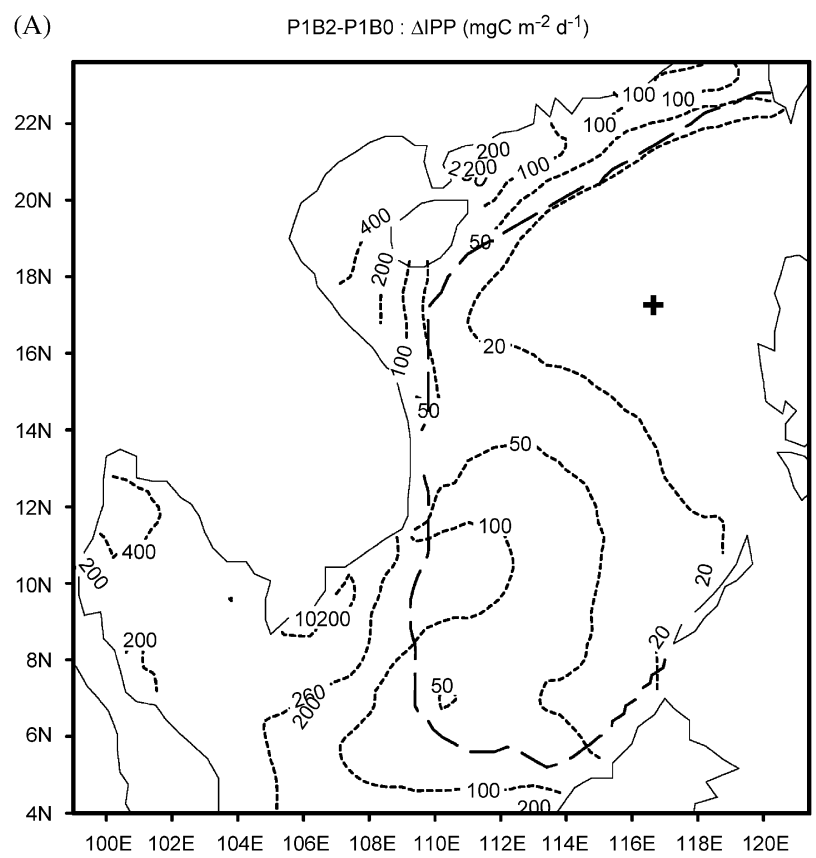

(B)

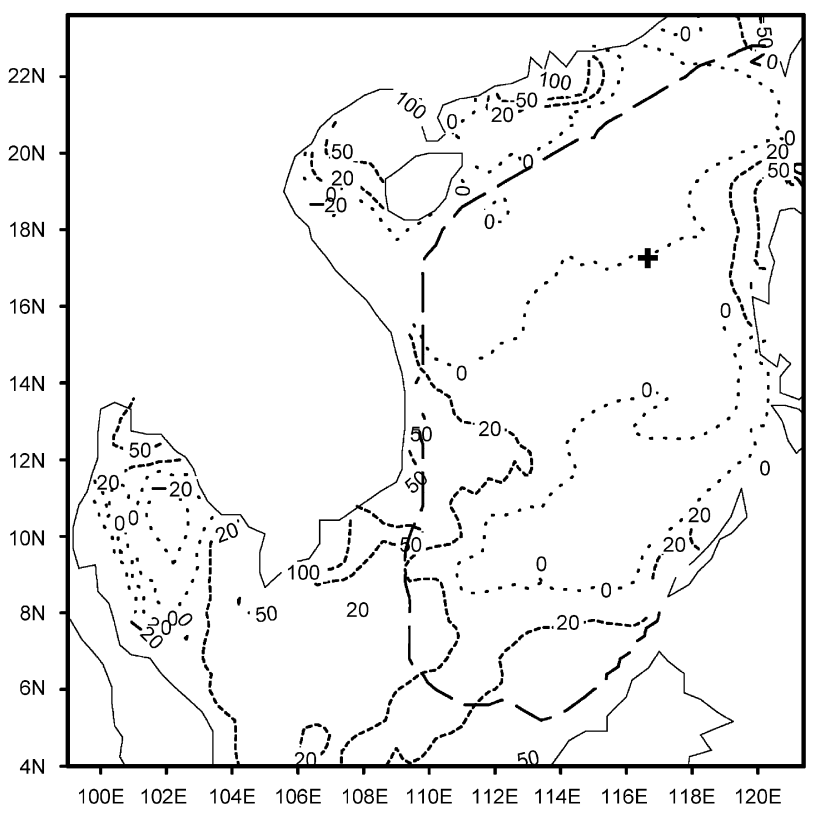

Fig. 16. The same as Fig. 14 except for the difference of modeled IPP ( $\left.\mathrm{mg} \mathrm{Cm}^{-2} \mathrm{~d}^{-1}\right)$. (A) P1B2-P1B0. (B) P1B1-P1B2. 
exhaustion of DIN in the top $50 \mathrm{~m}$ of the water column at the SEATS Station, as predicted by both models with photo-adaptation (Fig. 9) and shown by observations (Tseng et al., 2005), indicates the limitation of IPP by the availability of DIN in the surface layer. Because nearly all DIN pumped up from the subsurface layer has been consumed in both models, it is conceivable that further strengthening of photo-adaptation does not increase IPP. However, the benthic nutrient regeneration process has considerably raised the nutrient availability in the surface layer (Fig. 14), the strengthened photo-adaptation may further enhance primary productivity.

By including the benthic processes in the models with photo-adaptation schemes, we seek to detect any changes in IPP due to the combined effect. The results (Fig. 16B) show significant enhancement of IPP in areas where the nutrient is still readily available in the surface layer (Fig. 14B). The most enhanced IPP occurs in the continental shelf in the northern SCS, the southwestern SCS and the upper Gulf of Thailand. Slightly reduced IPP occurs in the including the SEATS Station, there is little change.

The annual average IPP predicted by Experiment $\mathrm{P} 2 \mathrm{~B} 2$ is shown in Fig. 17A. For comparison, the lower Gulf of Thailand. In the rest of the SCS,

annual average of the SeaWiFS data derived IPP is shown in Fig. 17B. Both images show occurrence of the lowest IPP values in the central basin southwest of Luzon and elevated IPP values in the shelf region $(<200 \mathrm{~m})$. However, the SeaWiFS data derived IPP values in the coastal zones are all very high ( $800 \mathrm{mg} \mathrm{C} \mathrm{m}^{-2} \mathrm{~d}^{-1}$ or higher), but the modeled IPP distributions show similar values only in the Bay of Tokin. The modeled IPP values are moderately high (600-700 $\mathrm{mg} \mathrm{C} \mathrm{m}^{-2} \mathrm{~d}^{-1}$ ) in the upwelling zone northwest of Luzon and southeast of Vietnam, but the SeaWiFS data-derived image shows more diffused distribution of intermediate IPP values ( $\sim 400 \mathrm{mg} \mathrm{C} \mathrm{m}^{-2} \mathrm{~d}^{-1}$ ) in these regions. The modeled IPP distribution shows very low IPP values $\left(\sim 200 \mathrm{mg} \mathrm{C} \mathrm{m}^{-2} \mathrm{~d}^{-1}\right)$ in the northern SCS, probably resulting from the intruding Kuroshio water. It has been demonstrated before that coarse horizontal resolution usually results in too strong a Kuroshio intrusion into the northern SCS (Metzger and Hurlburt, 2001).

Putting the spatial distribution aside, we are more concerned with the model skill of predicting the average primary production on the basin scale. For the comparison, we separate the domain into two regions, the shelf region with bottom depth less than $200 \mathrm{~m}$, and the basin with bottom depth greater

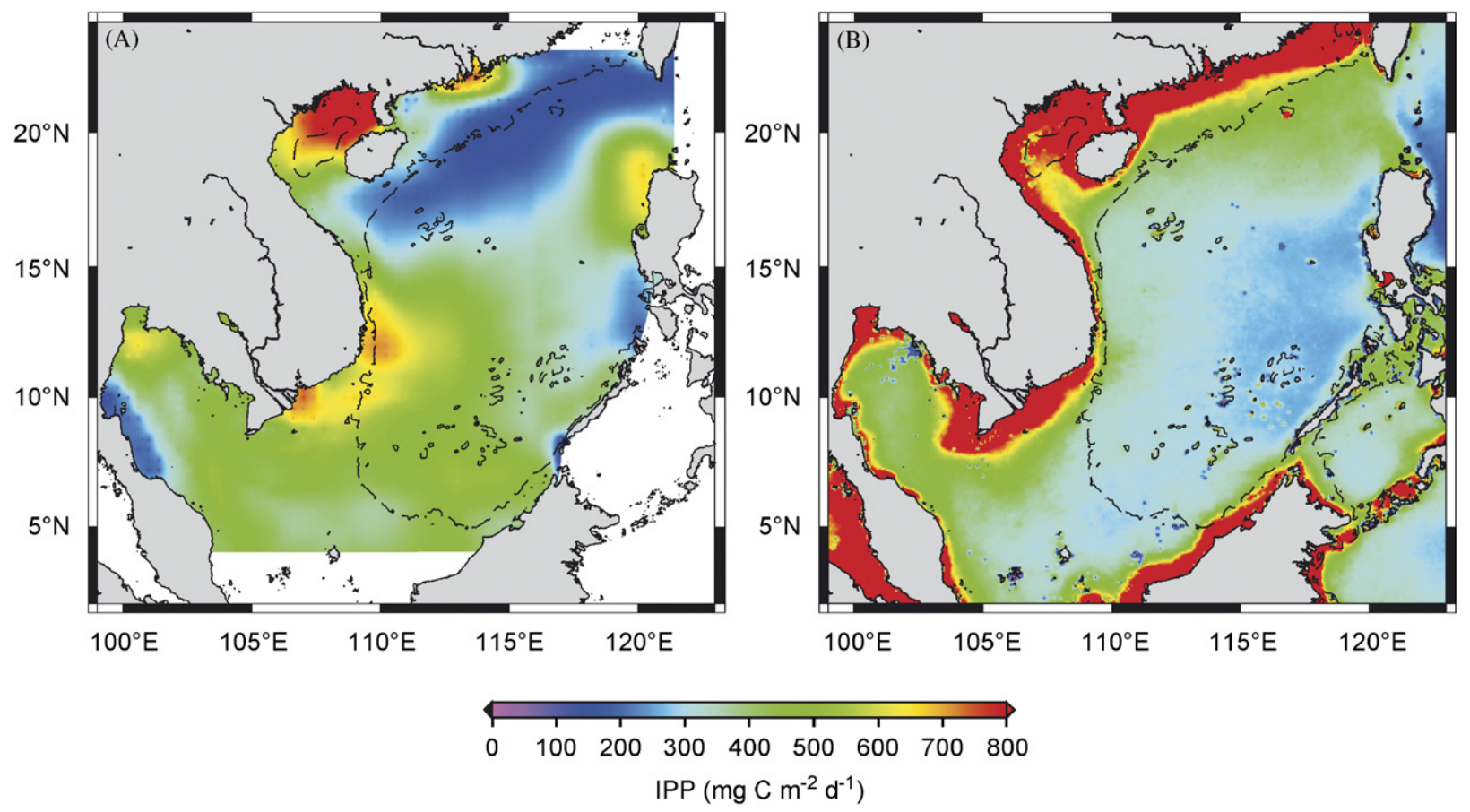

Fig. 17. Distribution of estimated annually averaged IPP $\left(\mathrm{mg} \mathrm{Cm}^{-2} \mathrm{~d}^{-1}\right)$ in the SCS. The long-dashed curve is the $200 \mathrm{~m}$ isobath. (A) Model results of P2B2. (B) SeaWiFS data derived results averaged over the period of 1998-2002. 
than $200 \mathrm{~m}$. The shelf domain has an area of 1.25 million $\mathrm{km}^{2}$ and the basin domain 1.89 million $\mathrm{km}^{2}$. The modeled IPP values are taken from Experiments P1B0 and P2B2 (Fig. 17A). For the basin region (Fig. 18A), P2B2 produces a stronger mean monthly IPP values than P1B0 by $59 \mathrm{mg} \mathrm{C} \mathrm{m}^{-2} \mathrm{~d}^{-1}$ on average, which is consistent with the results shown earlier (Fig. 16B).

Ning et al. (2004) surveyed IPP values throughout the SCS basin in summer and winter of 1998. The modeled mean IPP value from P2B2 for summer is quite close to the mean found by Ning et al. (2004), whereas the modeled value for winter is considerably lower than the observed mean (Fig. 18A). It is
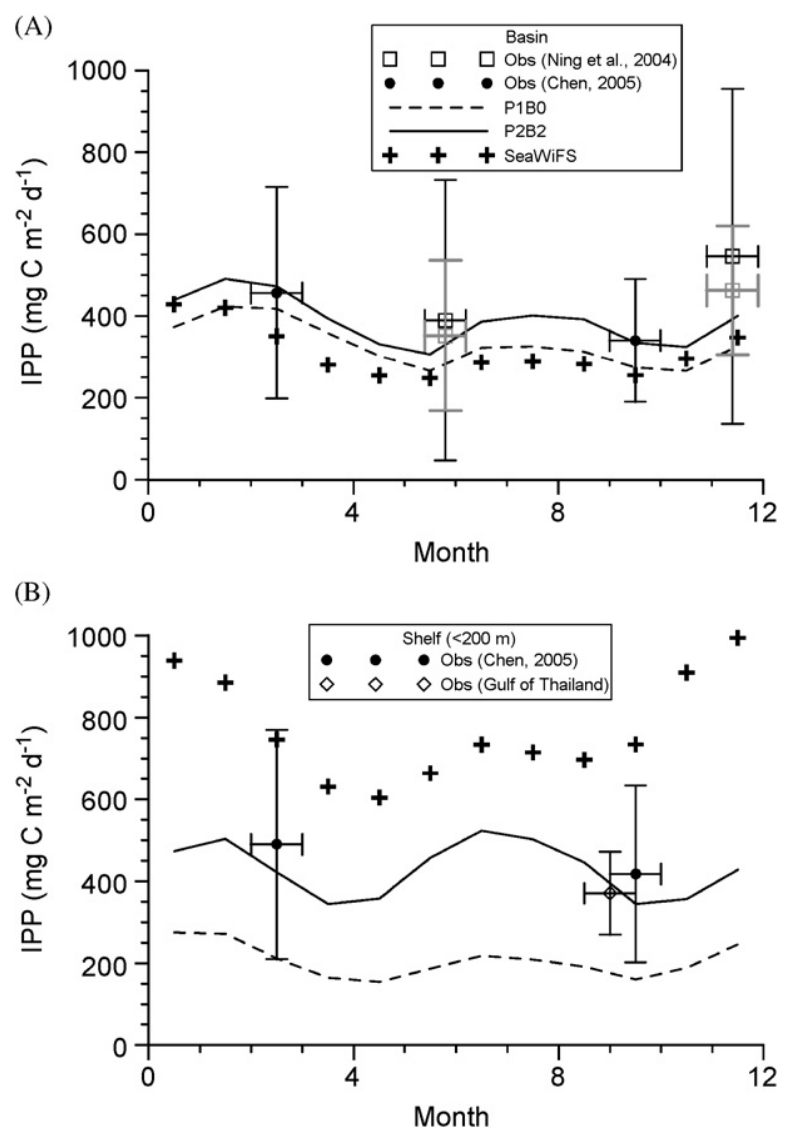

Fig. 18. Comparison between the observed mean IPP values $\left(\mathrm{mg} \mathrm{C} \mathrm{m}^{-2} \mathrm{~d}^{-1}\right)$ and the time-series curves of the modeled mean IPP in the basin $(>200 \mathrm{~m})$ and the shelf regions of the SCS, respectively. The horizontal bars represent durations of the observations and the vertical bars represent standard deviations of the observations. Also plotted are the monthly data of mean IPP derived from SeaWiFS data for the two regions. (A) For the basin region. The gray symbols represent results re-calculated from the data of Ning et al. (2004) for the basin region (see text). (B) For the shelf region. noted that both the sets of data of Ning et al. (2004) contain a very high value obtained in the upwelling area on the Sunda Shelf, which may have biased the mean values. We re-calculate the mean values by removing the Stations on the Sunda Shelf and two coastal stations in the northern SCS, where the productivities were actually quite low. The modeled IPP values of P2B2 match the new mean value of summer very well and fall short of the new winter mean value slightly. Although the surveys of Chen (2005) cover only the northern SCS, we plot the results for comparison. (Chen's results are calculated from her data obtained at the basin and slope stations.) For spring and fall the modeled IPP values match the averages of observed values of Chen (2005) very well (Fig. 18A). It is noted that Chen's mean IPP values for the northern SCS are at about the same level as those obtained over the entire basin by Ning et al. (2004).

The SeaWiFS data-derived mean monthly IPP values averaged over the basin region show a seasonal variation very similar to the modeled variations, but the magnitudes are all lower than those predicted by $\mathrm{P} 2 \mathrm{~B} 2$ and considerably lower than the observed mean values. This is contrary to the relationship demonstrated from the inter-comparison for the SEATS Station in Section 5.1.4 that the SeaWiFS data-derived IPP values match the observations well. It is likely that the underestimation of the SeaWiFS data-derived values on the basin scale results from the empirical relationship for the calculation of the $P_{\mathrm{opt}}^{\mathrm{B}}$ value, which is negatively correlated with temperature for temperatures above $20^{\circ} \mathrm{C}$ (Behrenfeld and Falkowski, 1997). The SST within the SCS is known to increase towards the south with the maximum annual mean value in the southernmost reaching $29^{\circ} \mathrm{C}$ (Chu et al., 1997), beyond the upper limit of the original data set for the formulation of the empirical relationship. The very high SST may have resulted in underestimation of the $P_{\mathrm{opt}}^{\mathrm{B}}$ values, which in turn may have caused underestimation of the IPP values in the southern SCS.

For the shelf region (Fig. 18B), the two models produces very different IPP values with the values from $\mathrm{P} 1 \mathrm{~B} 0$ being about half of the values predicted by $\mathrm{P} 2 \mathrm{~B} 2$. This is expected because the former has no benthic nutrient regeneration. The observed IPP values are few for the general shelf region. Most coastal studies cover only the near shore zones. For comparison, we plot the mean values for all the shelf stations in the northern SCS reported by Chen 
(2005) and also the results from the Gulf of Thailand discussed earlier. It is noted that the data points of Chen (2005) represent averages of data from her shelf stations and a coastal station. Despite their widely different localities, the two mean IPP values observed for the September-October period are similar (Fig. 18B). The modeled IPP values match these observations very well. For spring, the modeled values are also quite close to observations.

It is striking that the SeaWiFS data derived IPP values are about double the values predicted by P2B2. As noted earlier these IPP values for the coastal zone are quite high throughout the year. This contradicts the limited observations at coastal stations in the northern SCS, where the IPP values were in the range of $95-320 \mathrm{mg} \mathrm{C} \mathrm{m}^{-2} \mathrm{~d}^{-1}$ (Ning et al., 2004; Chen, 2005). It is known that the SeaWiFS chlorophyll data in the coastal zone are unreliable due to contamination by suspended solids and colored dissolve organic matter (Sathyendranath, 2000).

It turns out that only the SCS biogeochemical model is capable of producing the mean IPP values in reasonable agreement with observations on the basin-wide scale for both the deep $(>200 \mathrm{~m})$ and shallow regions. The annual mean IPP value over the basin region is $390 \mathrm{mg} \mathrm{C} \mathrm{m}^{-2} \mathrm{~d}^{-1}$ as predicted by P2B2, whereas the SeaWiFS data-derived IPP value is $312 \mathrm{mg} \mathrm{C} \mathrm{m}^{-2} \mathrm{~d}^{-1}$. The annual mean IPP value over the shelf region is $429 \mathrm{mg} \mathrm{C} \mathrm{m}^{-2} \mathrm{~d}^{-1}$ as predicted by $\mathrm{P} 2 \mathrm{~B} 2$, whereas the SeaWiFS dataderived mean IPP value is $771 \mathrm{mg} \mathrm{C} \mathrm{m}^{-2} \mathrm{~d}^{-1}$, which is a gross overestimation. The annual mean IPP value over the entire domain is thus estimated to be $405 \mathrm{mg} \mathrm{C} \mathrm{m}^{-2} \mathrm{~d}^{-1}$. Moreover, the SCS biogeochemical model is also capable of simulating the seasonal trend of phytoplankton growth derived from the SeaWiFS data. This confirms the notion that our SCS biogeochemical model catches the major features of the monsoon-driven biogeochemical processes in the SCS.

Comparisons of results from different numerical experiments reveal that inclusion of the benthic nutrient regeneration accounts for 39\% increase of primary production in the SCS as a whole with respect to that of the original model; enhancement of photo-adaptation by increasing the $R_{\mathrm{L}}$ value from 2.5 to 3.5 may increase primary production by another $5 \%$. Without photo-adaptation, the SCS would be less productive than that represented by the original model by about $35 \%$.

\subsubsection{Rates of benthic denitrification and nitrification}

The denitrification rate is calculated as the flux of DIN removed at the bottom boundary using Eq. (7). The average of the output from P2B2 over the 1-year period is presented in Fig. 19. The average distribution shows that denitrification is most intense in the inner shelf with maximum values of annual mean reaching $100 \mathrm{mmol} \mathrm{N} \mathrm{m}^{-2} \mathrm{a}^{-1}$ or higher. Over the continental shelf, the flux remains mostly between 20 and $80 \mathrm{mmol} \mathrm{N} \mathrm{m}^{-2} \mathrm{a}^{-1}$. The flux decreases rapidly down the slope and reaches $1 \mathrm{mmol} \mathrm{N} \mathrm{m} \mathrm{a}^{-1}$ or less in the deep basin.

The average over the entire continental shelf of the SCS is $66 \mathrm{mmol} \mathrm{N} \mathrm{m}^{-2} \mathrm{a}^{-1}$ or $0.16 \mathrm{mmol} \mathrm{N} \mathrm{m}^{-2} \mathrm{~d}^{-1}$, which is considerably lower than those $(635 \pm$ $200 \mathrm{mmol} \mathrm{N} \mathrm{m}^{-2} \mathrm{a}^{-1}$ ) observed in the coastal sediments in the Mid Atlantic Bight (Laursen and Seitzinger, 2002). However, the value is on the same order of magnitude as the downward fluxes of nitrate, $\quad 13-34 \mathrm{mmol} \mathrm{N} \mathrm{m}^{-2} \mathrm{a}^{-1}$, observed in the muddy sediments of the Bay of Biscay (Hyacinthe et al., 2001) and also resembles the observed denitrification fluxes of $17-53 \mathrm{mmol} \mathrm{N} \mathrm{m}^{-2} \mathrm{a}^{-1}$ in the Baltic Sea (Stockenberg and Johnstone, 1997). The overall removal rate of DIN during denitrification in the SCS is estimated at $92 \mathrm{Gmol} \mathrm{N} \mathrm{a}^{-1}$, which is dominated by denitrification on the continental shelf $\left(78 \mathrm{Gmol} \mathrm{Na}^{-1}\right)$. The latter estimate is rather close to the riverine input of DIN $\left(70 \mathrm{Gmol} \mathrm{Na}^{-1}\right)$ to the SCS assumed in this model.

Since the removal flux of DIN during denitrification is modeled as a fixed fraction $(14 \%)$ of the detritus flux that hits the bottom, the latter may be calculated from the modeled denitrification strength. Then the total flux of detritus (PON) reaching the bottom is calculated to be $660 \mathrm{Gmol} \mathrm{Na}^{-1}$, which may be converted to a total POC flux of $45.1 \mathrm{TgC}^{-1}$. For the shelf region, the total detritus flux is $558 \mathrm{GmolNa}^{-1}$, of which $480 \mathrm{Gmol} \mathrm{Na}^{-1}$ is regenerated as DIN. The per unit area flux is $1.06 \mathrm{mmol} \mathrm{N} \mathrm{m} \mathrm{m}^{-2} \mathrm{~d}^{-1}$, which may support a productivity of $84 \mathrm{mg} \mathrm{C} \mathrm{m}^{-2} \mathrm{~d}^{-1}$ of phytoplankton growth.

\section{Discussion and summary}

It is demonstrated conclusively that photo-adaptation is a critical process to the phytoplankton growth in the SCS. The observed POC/Chl- $a$ ratios display a decreasing trend in the upper euphotic zone and a reversal of the trend in the lower part. 


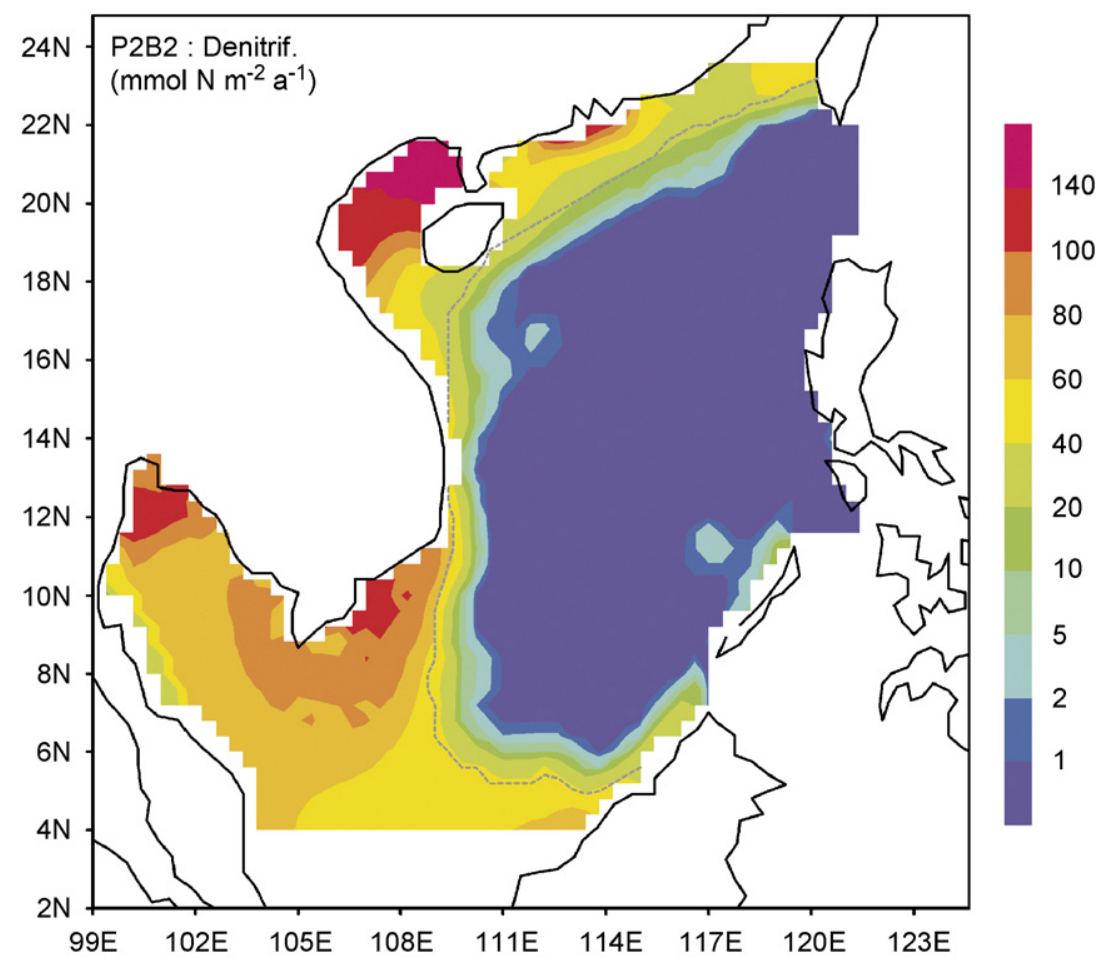

Fig. 19. Modeled flux ( $m$ mol N m $\mathrm{m}^{-2} \mathrm{a}^{-1}$ ) of DIN removal during benthic denitrification in the SCS predicted by Experiment P2B2. The gray dashed curve represents the $200 \mathrm{~m}$ isobath, which separates the shelf and the basin regions.

The model with photo-adaptation is capable of generating a similar trend of the POC/Chl- $a$ ratio. More importantly the modeled $\mathrm{OC}_{\mathrm{Phy}} / \mathrm{Chl}-a$ ratio mimics the lower limit of the observed distributions of POC/Chl- $a$ ratios in the upper euphotic zone. These observations provide direct evidence for the variable chlorophyll-to-nitrogen ratio in phytoplankton adopted by the model. Without photo-adaptation, the phytoplankton growth becomes quite inefficient resulting in much reduced primary productivity by as much as $35 \%$. The observed POC/Chl- $a$ ratios show seasonal changes with the lowest values occurring in winter and spring. This is consistent with the observed enhancement of cellular fluorescence in these seasons. Observations also suggest that the upper limit of the $\mathrm{Chl} / \mathrm{Phy}$ ratio under low light conditions is probably higher than that (2.5) used in the original model. Adoption of a higher value of 3.5 enhances the modeled Chl- $a$ concentrations in the lower euphotic zone and brings the modeled Chl- $a$ distribution closer to the observations in most cases. However, this change does not enhance the IPP value under nutrient limiting conditions, but it still increases the average IPP in the entire SCS by $5 \%$, mostly attributed to the nutrient replete shelf region.

The observed IPP values in the Gulf of Thailand provides an essential reference, against which the predicted IPP values from the original model are shown to be grossly underestimated due to the lack of benthic nutrient regeneration. Inclusion of benthic nutrient regeneration in the model builds up rather high nutrient concentrations in the Gulf of Thailand and strongly enhances primary productivity. It becomes clear that the rather low mean annual value of vertically IPP in the SCS estimated previously by Liu et al. (2002) is mainly attributed to the lack of benthic regeneration of nutrients.

It is further demonstrated that, without denitrification, the modeled IPP becomes too strong with intensity exceeding the observed IPP. Adoption of a recommended denitrification rate of $14 \%$ of the particulate nitrogen flux hitting the sea floor (Fennel et al., 2006) produces an IPP distribution resembling the observations. The effect of the benthic nutrient regeneration is not limited to the shelf region, but spreads to the basin region, especially in the southwestern half of the SCS basin. Consequently, the benthic-pelagic coupling enhances 
primary productivity not only in the shelf region but also in the basin region with an overall enhancement attaining 39\%. The modeled mean monthly IPP values match the observed mean values rather well for both the basin region and the shelf region. The annual mean IPP is estimated to be $390 \mathrm{mg} \mathrm{C} \mathrm{m}^{-2} \mathrm{~d}^{-1}$ for the basin region, $429 \mathrm{mg} \mathrm{C} \mathrm{m}^{-2} \mathrm{~d}^{-1}$ for the shelf region and $406 \mathrm{mg} \mathrm{C} \mathrm{m}^{-2} \mathrm{~d}^{-1}$ for the entire SCS.

The removal rate of DIN in the entire SCS is estimated to be $92.4 \mathrm{Gmol} \mathrm{N} \mathrm{a}^{-1}$, of which $85 \%$ is attributed to the shelf region with water depth less than $200 \mathrm{~m}$. The average DIN flux removed during denitrification in the shelf region is $0.16 \mathrm{mmol} \mathrm{N} \mathrm{m}^{-2} \mathrm{~d}^{-1}$, which corresponds to a POC flux of $13 \mathrm{mg} \mathrm{Cm}^{-2} \mathrm{~d}^{-1}$, about $3 \%$ of the modeled IPP.

There is still plenty of room for improvement of the model, which is not satisfactory in predicting the spatial distribution of IPP in the SCS. As pointed out before (Liu et al., 2002), the coarse resolution of the model results in too much horizontal mixing but not enough lateral advection. Consequently, the upwelled nutrients tend to remain in the upwelling regions and their immediate adjacent areas. Refining of the horizontal resolution and adopting of the daily or even $6 \mathrm{~h}$ wind forcing (Wu and Chiang, 2007) are probably necessary to improve the spatial distribution pattern. Moreover, the modeled SCM is often too shallow and cannot account for the substantial amount of Chl- $a$ in the lower part of the euphotic zone. Both the physical processes controlling the mixed layer and the ecosystem structure and parameterization are responsible for the discrepancy. Apart from adopting a hydrodynamic model with finer resolution, this discrepancy calls for modification of the ecosystem model by including more observed biological parameters in the model (Liu et al., 2007) and by adopting more up-to-date algorithms for acclimation of phytoplankton growth (Geider et al., 1998; Christian, 2005; Pahlow, 2005). The model in its present form serves as a good foundation, from which more sophisticated models may emerge.

Recently, a new modeling effort for the SCS biogeochemistry has been initiated (Chai et al., 2006) based on different hydrodynamic and ecosystem models. The improved model of this study may serve as the basis for model comparison, once the new model is established. Additionally, the investigation of the role of benthic processes in this study may prove useful for better understanding of glacial-interglacial differences in paleoceanographic conditions in the SCS. It is well accepted that the sea level in the SCS was lower than the current level by as much as $120 \mathrm{~m}$ during the last glacial maximum (Hanebuth et al., 2000). Consequently, the SCS essentially had no continental shelves during the last glacial maximum. According to this study, the lack of benthic nutrient regeneation in the shelves should have discernible effects on the production of OC on the southwestern slope of the SCS. Further investigation along this line is promising.

\section{Acknowledgments}

This study was supported by the Grant NSC 942611-M-008-002 from the National Science Council of the Republic of China. We thank the captains and crew of the R/V Ocean Researcher I and R/V Ocean Researcher III for sampling assistance. This paper benefits from constructive comments from two anonymous reviewers. One of us (KKL) is especially grateful to Katja Fennel, who made then unpublished manuscript on modeling of hers available to us. This is NCU-IHS Contribution \#54.

\section{References}

Behrenfeld, M.J., Falkowski, P.G., 1997. Photosynthetic rates derived from satellite-based chlorophyll concentrations. Limnology and Oceanography 42, 1-20.

Chai, F., Liu, G., Shi, L., Xue, H., Chao, Y., Liu, K.-K., Tseng, C.-M., 2006. Seasonal and Interannual Variability of Ecosystem Dynamics and Carbon Cycle in South China Sea: A Three-Dimensional Physical-Biogeochemical Modeling Study. Am. Geophys. Union Ocean Sciences Meeting, Honolulu.

Chao, S.Y., Shaw, P.T., Wu, S.Y., 1996. Deep-water ventilation in the South China Sea. Deep-Sea Research I 43 (4), 445-466.

Chen, Y.L.L., 2005. Spatial and seasonal variations of nitratebased new production and primary production in the South China Sea. Deep-Sea Research I 52 (2), 319-340.

Chen, C.C., Shiah, F.K., Chung, S.W., Liu, K.K., 2006. Winter phytoplankton blooms in the shallow mixed layer of the South China Sea enhanced by upwelling. Journal of Marine Systems 59 (1-2), 97-110.

Chen, M.T., Wang, C.H., Huang, C.Y., Wang, P.X., Wang, L.J., Sarnthein, M., 1999. A late quaternary planktonic foraminifer faunal record of rapid climatic changes from the South China Sea. Marine Geology 156 (1-4), 85-108.

Chongprasith, P., Srinetr, V., 1998. Marine water quality and pollution of the Gulf of Thailand. In: Johnston, D.M. (Ed.), ISEAPOL Integrated Studies of the Gulf of Thailand, vol. 1. Southeast Asian Programme in Ocean Law, Policy and Management, Thailand, pp. 137-204.

Christian, J.R., 2005. Biogeochemical cycling in the oligotrophic ocean: Redfield and non-Redfield models. Limnology and Oceanography 50 (2), 646-657. 
Chu, P.C., Lu, S., Chen, Y., 1997. Temporal and spatial variabilities of the South China Sea surface temperature anomaly. Journal of Geophysical Research 102 (C9), 20937-20956.

Conkright, M.E., Levitus, S., Boyer, T.P., 1994. World Ocean Atlas 1994, Volume 1: Nutrients. NOAA Atlas NESDIS 1, US Printing Office, Washington D.C., 162pp.

Doney, S.C., Glover, D.M., Najjar, R.G., 1996. A new coupled, one-dimensional biological-physical model for the upper ocean-applications to the JGOFS Bermuda Atlantic timeseries study (BATS) site. Deep-Sea Research II 43 (2-3), 591-624.

Fasham, M.J.R., Ducklow, H.W., McKelvie, S.M., 1990. A nitrogen-based model of plankton dynamics in the oceanic mixed layer. Journal of Marine Research 48 (3), 591-639.

Fennel, K., Wilkin, J., Levin, J., Moisan, J., O'Reilly, J., Haidvogel, D., 2006. Nitrogen cycling in the middle Atlantic Bight: results from a three-dimensional model and implications for the north Atlantic nitrogen budget. Global Biogeochem. Cycles 20, GB3007.

Furuya, K., 1990. Subsurface chlorophyll maximum in the tropical and subtropical western Pacific Ocean: vertical profiles of phytoplnakton biomass and its relationship with chlorophyll a and particulate organic carbon. Marine Biology 107, 529-539.

Geider, R.J., 1987. Light and temperature-dependence of the carbon to chlorophyll-a ratio in microalgae and cyanobacteria-implications for physiology and growth of phytoplankton. New Phytology 106 (1), 1-34.

Geider, R.J., MacIntyre, H.L., Kana, T.M., 1998. A dynamic regulatory model of phytoplanktonic acclimation to light, nutrients, and temperature. Limnology and Oceanography 43 (4), 679-694.

Hanebuth, T., Stattegger, K., Grootes, P.M., 2000. Rapid flooding of the Sunda Shelf: a late-glacial sea-level record. Science 288, 1033-1035.

Hellerman, S., Rosenstein, M., 1983. Normal monthly wind stress over the world ocean with error-estimates. Journal of Physical Oceanography 13, 1093-1104.

Hyacinthe, C., Anschutz, P., Carbonel, P., Jouanneau, J.M., Jorissen, F.J., 2001. Early diagenetic processes in the muddy sediments of the Bay of Biscay. Marine Geology 177 (1-2), 111-128.

Jassby, A.D., Platt, T., 1976. Mathematical formulation of the relationship between photosynthesis and light for phytoplankton. Limnology and Oceanography 21, 540-547.

Laursen, A.E., Seitzinger, S.P., 2002. The role of denitrification in nitrogen removal and carbon mineralization in Mid-Atlantic Bight sediments. Continental Shelf Research 22 (9), 1397-1416.

Levitus, S., 1982. Climatological atlas of the world ocean. NOAA Professional paper No. 13, US, Government Printing Office, Washington, D.C., 173pp.

Liu, K.K., Chao, S.Y., Shaw, P.T., Gong, G.C., Chen, C.C., Tang, T.Y., 2002. Monsoon-forced chlorophyll distribution and primary production in the South China Sea: observations and a numerical study. Deep-Sea Research I 49 (8), $1387-1412$.

Liu, K.-K., Chao, S.-Y., Marra, J., Snidvongs, A., 2006. Monsoonal forcing and biogeochemical environments of outer Southeast Asia Seas. In: Robinson, A., Brink, K.H. (Eds.), The Sea, vol. 14A, The Global Coastal Ocean:
Interdisciplinary Regional Studies and Synthesis. Harvard University Press, Cambridge, pp. 673-721.

Liu, H., Chang, J., Tseng, C.-M., Wen, L.-S., Liu, K.-K., 2007. Seasonal variability of picoplankton in the South China Sea at South East Asia time-series station (SEATS). Deep-Sea Research II 1, 234 (this issue).

McGillicuddy, D.J., McCarthy, J.J., Robinson, A.R., 1995. Coupled physical and biological modeling of the spring bloom in the North Atlantic (I): model formulation and onedimensional bloom processes. Deep-Sea Research I 42, 1313-1357.

Metzger, E.J., Hurlburt, H.E., 2001. The importance of high horizontal resolution and accurate coastline geometry in modeling South China Sea inflow. Geophysical Research Letters 28 (6), 1059-1062.

Moore, J.K., Doney, S.C., Kleypas, J.A., Glover, D.M., Fung, I.Y., 2002. An intermediate complexity marine ecosystem model for the global domain. Deep-Sea Research II 49 (1-3), 403-462.

Morel, A., Berthon, J.F., 1989. Surface pigments, algal biomass profiles, and potential production of the euphotic layer: relationships reinvestigated in view of remote-sensing applications. Limnology and Oceanography 34, 687-701.

Musikasung, W., Yusoff, M.S.B., Razak, S.B.A., 1997. Primary production determination in the South China Sea, Area I: Gulf of Thailand and east coast of Peninsular Malaysia. in Proceedings of the First Technical Seminar on Marine Fishery Resources Survey in The South China Sea, Area I: Gulf Of Thailand and Peninsular Malaysia. Southeast Asia Fisheries Development Center, Bangkok, Thailand, pp. 135-146.

NGDC, 2001. ETOPO2 Global 2-Minute Gridded Elevation Data Volume E1. National Geophysical Data Center. National Oceanographic and Atmospheric Agency, USA.

Ning, X., Chai, F., Xue, H., Cai, Y., Liu, C., Zhu, G., Shi, J., 2004. Physical-biological oceanographic coupling influencing phytoplankton and primary production in the South China Sea. Journal of Geophysical Research 109, C10005.

Pahlow, M., 2005. Linking chlorophyll-nutrient dynamics to the Redfield N:C ratio with a model of optimal phytoplankton growth. Marine Ecology-Progress Series 287, 33-43.

Parsons, T.R., Maita, Y., Lalli, C.M., 1984. A manual of Chemical And Biological Methods For Seawater Analysis. Pergamon Press, New York.

Sathyendranath, S., 2000. Remote sensing of ocean color in coastal and other optically-complex waters. Reports of the International Ocean-Color Coordinating Group, 3, IOCCG, Dartmouth, Canada.

Shaw, P.T., 1991. The seasonal-variation of the intrusion of the Philippine Sea-water into the South China Sea. Journal of Geophysical Research 96, 821-827.

Shaw, P.T., Chao, S.Y., 1994. Surface circulation in the South China Sea. Deep-Sea Research I 41 (11-12), 1663-1683.

Shaw, P.T., Chao, S.Y., Liu, K.K., Pai, S.C., Liu, C.T., 1996. Winter upwelling off Luzon in the northeastern South China Sea. Journal of Geophysical Research 101 (C7), $16435-16448$.

Smith, S.L., 2001. Understanding the Arabian Sea: reflections on the 1994-1996 Arabian Sea expedition. Deep-Sea Research II 48 (6-7), 1385-1402.

Soetaert, K., Middelburg, J.J., Herman, P.M.J., Buis, K., 2000. On the coupling of benthic and pelagic biogeochemical models. Earth-Science Reviews 51 (1-4), 173-201. 
Stockenberg, A., Johnstone, R.W., 1997. Benthic denitrification in the Gulf-of-Bothnia. Estuarine Coastal and Shelf Science $45,835-843$.

Strickland, J.D.H., Parsons, T.R., 1972. A Practical Handbook Of Seawater Analysis. Fisheries Research Board of Canada, Ottawa, Canada, 310pp.

Tseng, C.M., Wong, G.T.F., Lin, I.I., Wu, C.R., Liu, K.K., 2005. A unique seasonal pattern in phytoplankton biomass in lowlatitude waters in the South China Sea. Geophysical Research Letters 32, L08608.

Udarbe-Walker, M.J.B., Villanoy, C.L., 2001. Structure of potential upwelling areas in the Philippines. Deep-Sea Research I 48 (6), 1499-1518.

Wang, P.X., Tian, J., Cheng, X.R., Liu, C.L., Xu, J., 2004. Major Pleistocene stages in a carbon perspective: the South China Sea record and its global comparison. Paleoceanography 19, PA4005.

Wattayakorn, G., King, B., Wolanski, E., Suthanaruk, P., 1998. Seasonal dispersion of petroleum contaminants in the Gulf of Thailand. Continental Shelf Research 18, 641-659.

Wollast, R., 1993. Interactions of carbon and nitrogen cycles in the coastal zone. In: Wollast, R., Mackenzie, F.T., Chou, L.
(Eds.), Interactions of C, N, P and S Biogeochemical Cycles and Global Change. Springer, Berlin, pp. 195-210.

Wong, G.T.F., Chung, S.W., Shiah, F.K., Chen, C.C., Wen, L.S., Liu, K.K., 2002. Nitrate anomaly in the upper nutricline in the northern South China Sea-evidence for nitrogen fixation. Geophysical Research Letters 29 (23), 2097.

Wu, C.-R., Chiang, T.-L., 2007. Mesoscale eddies in the northern South China Sea. Deep-Sea Research II (this issue).

Wu, C.R., Shaw, P.T., Chao, S.Y., 1999. Assimilating altimetric data into a South China Sea model. Journal of Geophysical Research 104 (C12), 29987-30005.

Wyrtki, K., 1961. Physical oceanography of the South-east Asian waters. NAGA Report Scientific Results of Marine Investigations of the South China Sea and the Gulf of Thailand. Scripps Institution of Oceanography, La Jolla, California, 195pp.

Xue, H.J., Chai, F., Pettigrew, N., Xu, D.Y., Shi, M., Xu, J.P., 2004. Kuroshio intrusion and the circulation in the South China Sea. Journal of Geophysical Research 109, C02017.

Yang, Y., Liu, K.-K., Liu, C.-T., 2004. Decoupled thermal structure in association with propagating eddies in the Northern South China Sea. OS52A-01. Western Pacific Geophysics Meeting, Honolulu, 16-20, August 2004. 